\title{
Reference guide for data collection: Qualitative social network interviews
}

Bettina Shell-Duncan

Amadou Moreau

Sarah Smith

Holly B. Shakya

Follow this and additional works at: https://knowledgecommons.popcouncil.org/departments_sbsr-rh

Part of the International Public Health Commons, Sociology of Culture Commons, and the Women's Health Commons How does access to this work benefit you? Let us know!

\section{Recommended Citation}

Shell-Duncan, Bettina, Amadou Moreau, Sarah Smith, and Holly B. Shakya. 2019. "Reference guide for data collection: Qualitative social network interviews." Evidence to End FGM/C: Research to Help Girls and Women Thrive. New York: Population Council. 


\title{
A REFERENCE GUIDE
}

The purpose of this document is to guide researchers who plan to use qualitative social network methods drawing on our experiences implementing a qualitative study entitled, "The End of Female Genital Mutilation/Cutting in Senegal: Tracing Social Networks, Investigating the Role of Gender and Intergenerational Influence."

\author{
Bettina Shell-Duncan, University of Washington, Seattle, Washington, USA \\ Amadou Moreau, Global Research and Advocacy Group, Dakar, Senegal \\ Sarah Smith, Global Research and Advocacy Group, Dakar, Senegal \\ Holly Shakya, University of California, San Diego, California USA
}

\section{OVERVIEW}

Humans are embedded in a thick web of social interactions, which form patterns of social networks. The study of social networks_-both quantitatively and qualitativelyhas emerged as a powerful approach for studying how interpersonal connections influence a person's attitudes and behaviors. The primary concern of all network analysis studies is social relationships and how these relationships are structured. Rather than focusing exclusively on traits of individuals, network studies include an expanded focus to capture the social context in which individuals are embedded, patterns of social interaction, and the extent to which these interactions can influence preferences, adherence to norms, and decisionmaking. It is through social interactions that two key processes occur: social learning (learning the social norms in particular contexts) and social influence (enforcement of the norms through positive or negative sanctions). Patterns of influence may vary based on factors such as strength of social ties, hierarchies of authority, and social status and roles.

While quantitative methods have dominated the field of network analysis in recent decades, there has lately been a resurgence in interest in qualitative network paradigms, either as stand-alone approaches or in combination with quantitative network studies. This interest stems from the growing appreciation that qualitative network studies can illuminate social meanings and norms that arise from social interaction and provide rich descriptive information on the contexts in which interactions take place.

The purpose of this document is to guide researchers who plan to use qualitative social network methods drawing on our experiences implementing a qualitative study entitled, "The End of Female Genital Mutilation/Cutting in Senegal: Tracing Social Networks, Investigating the Role of Gender and Intergenerational Influence." Qualitative fieldwork was carried out in two contrasting settings in Senegal: 1) a region with a low prevalence of female genital mutilation/ cutting (FGM/C) characterized by ethnic heterogeneity, and 2) a region with a high prevalence of $F G M / C$ characterized by relative ethnic homogeneity. The goal of this research was to investigate the ways in which social interactions and social influence vary along dimensions including gender, class, and generation, and how they influence the dynamics of decisionmaking regarding FGM/C. More specifically, the objectives of the study were to:

- Investigate the decisionmaking process regarding continuation, change, or abandonment of the practice of $\mathrm{FGM} / \mathrm{C}$.

- Identify interdependent social norms, including gender norms, that serve to uphold or challenge the practice of $\mathrm{FGM} / \mathrm{C}$, and the means by which these norms are enforced or contested. 
- Assess the nature, influence, and importance of interactions among social network members in deciding whether to uphold, alter, or abandon the practice of $\mathrm{FGM} / \mathrm{C}$, and identify when and how men are involved in these networks.

- Identify characteristics of people who occupy positions as influential leaders, such as age, gender, and social status, and trace path-dependent networks through which their influence may operate.

- $\quad$ Explore how an improved understanding of network influences on FGM/C may be used to optimize intervention strategies.

In this document, we briefly describe social network concepts and qualitative approaches as well as share the tools and training materials developed for implementing the qualitative social network methods employed in this study. While this study is focused on the topic of FGM/C, these methods can be modified and adapted to the study of other health-related behaviors. Hence, we offer lessons learned throughout our data collection, management, and analysis process.

\section{SOCIAL NETWORK CONCEPTS AND QUALITATIVE APPROACHES}

While the scientific study of networks has been ongoing for decades, network methods have become highly formalized in recent years due to mathematical developments and user-friendly software for visualizing and measuring social networks (Edwards 2010; Hollstein 2014). These methods have been used to generate innovative research on a wide range of health topics including HIV transmission through sexual networks (Morris 1997), substance abuse (Valente, Mouttapa, and Gallaher 2004), smoking (Alexander et al. 1987; Bauman and Ennett 1994), contraceptive use (Valente et al. 1997), child nutrition (Moestue et al. 2007), risk factors for sexual violence against adolescent girls (Shakya et al. 2017), obesity (Christakis and Fowler 2007), and vaccination (Brunson 2013). These studies provide an indepth understanding of how behaviors are distributed within a social (or sexual) network and offer insights on factors associated with behavior change.

One of the most potent ideas in network theory is that individuals are embedded within a thick web of social interaction, and that these interactions influence behavior (Behrman, Kohler, and Watkins 2002; Valente et al. 1997). Social network data enable us to determine how people are interconnected, how people cluster according to various characteristics, how people's place within their social context may increase or decrease their probability of exhibiting a certain behavior or adopting new practices, and hence how they might influence one another. In short, social network analysis (SNA) offers a new way to understand the motivations for upholding or changing behavior, moving beyond individual attributes (such as the location, education, wealth, etc., of a particular individual), and capturing collective attributes (such as the structure of the social network in which the individual is embedded). One robust finding is that interpersonal relationships often influence a person's behavior above and beyond the influence of his or her own attributes (even individual preferences) (e.g., Brunson 2013).

The ultimate goal of social network studies is to analyze the effects of social interaction on behavior, as well as the formation, enforcement, and possible change in social norms. Analytic methods in the burgeoning field of SNA provide powerful means for gaining insights into the effects of social interaction and social influence that can be used to optimize intervention strategies.

\section{SOCIAL NETWORK ANALYSIS}

Social network analysis was first introduced in the 1950s in the field of anthropology through ethnographic studies in small-scale social settings, with a focus on social structure and interpersonal relationships (Barnes 1954; Bott 1957; Mitchell 1969). Quantitative methods of analyzing social network data were initiated in fields such as sociology, but their development was somewhat slow until computing technologies were developed in the 1970s to support rigorous computations. This spurred a dramatic expansion in quantitative network analysis, with a focus on structural properties of social networks that influence the diffusion of innovation in social norms and practices (Valente 2010). While quantitative approaches to the study of social networks has dominated the field for several decades, the quantitative paradigm has also drawn criticism for focusing heavily on the architecture of social networks while having limited reflection on the meanings and norms that arise from social interactions, and the inability to tease out the nuances of social context (Hollstein 2014). More recently, there has been a resurgence of interest in qualitative methods, either as a stand-alone approach or in combination with quantitative methods, and the expansion of qualitative approaches to the study of social networks (Edwards 2010; Hogan, Carrasco, and Wellman 2007; Hollstein 2014). 
The primary concern of all SNA studies is social relationships, how these relationships are structured, and how social interactions shape social learning (that is, learning about what is commonly practiced in particular contexts) and social influence (enforcement of the social norms through positive or negative sanctions). The focus on social interaction is what makes SNA different from other study approaches, which tend to focus exclusively or predominantly on the traits of individuals. In SNA it is the ties between individuals that are the object of study. Commonly studied ties include friendship and kinship ties, communication, advice giving, sexual ties, or most basic of all, acquaintanceship. These ties represent conduits for the flow of information, social support, social pressure, resources, and more. In the study of health behaviors, an important observation is that individuals rarely make decisions in isolation; instead they are often influenced by the people who surround them directly and indirectly (e.g., friends of friends). Hence, social network studies focus on the social context in which individuals are embedded, and the extent to which and ways that this context can influence preferences, norms, and decisions. For instance, previous social network studies of mothers' decisionmaking have found that network-level factors are often better predictors of health-related behaviors than individual characteristics of the mother herself, including her age, parity, marital status, economic status, and even her own preferences. In a study on breastfeeding, for example, Fonseca-Becker and Valente (2006) found a strong association between social networks and mothers' knowledge of breastfeeding. Researching both men and women living in urban areas of Bolivia, the authors found that the social networks added to the predictive power of individual variables for breastfeeding knowledge, and that network characteristics influenced breastfeeding behaviors of mothers. Similar findings on the role of social networks on mothers' decisionmaking have been found in studies on children's access to primary health care (Buetow 2005), child vaccination (Brunson 2013), and child feeding (Moestue et al. 2007). Therefore, it is apparent that an understanding of the social context can greatly enhance understandings of health behaviors and behavior change.

Network methodologies on decisionmaking can offer novel insights not afforded by other methodologies by providing information on patterns of social interaction. It is through these interactions that two key processes occur: social learning and social influence. This influence can come as network partners learn about the norms, values, and preferences of others in their social group, and develop a
FIGURE 1. FUNDAMENTAL CONCEPTS ABOUT SOCIAL NETWORKS: A. NODES AND TIES; B. DEGREE OF A NODE; C. CLUSTERING; AND D. CLIQUES.

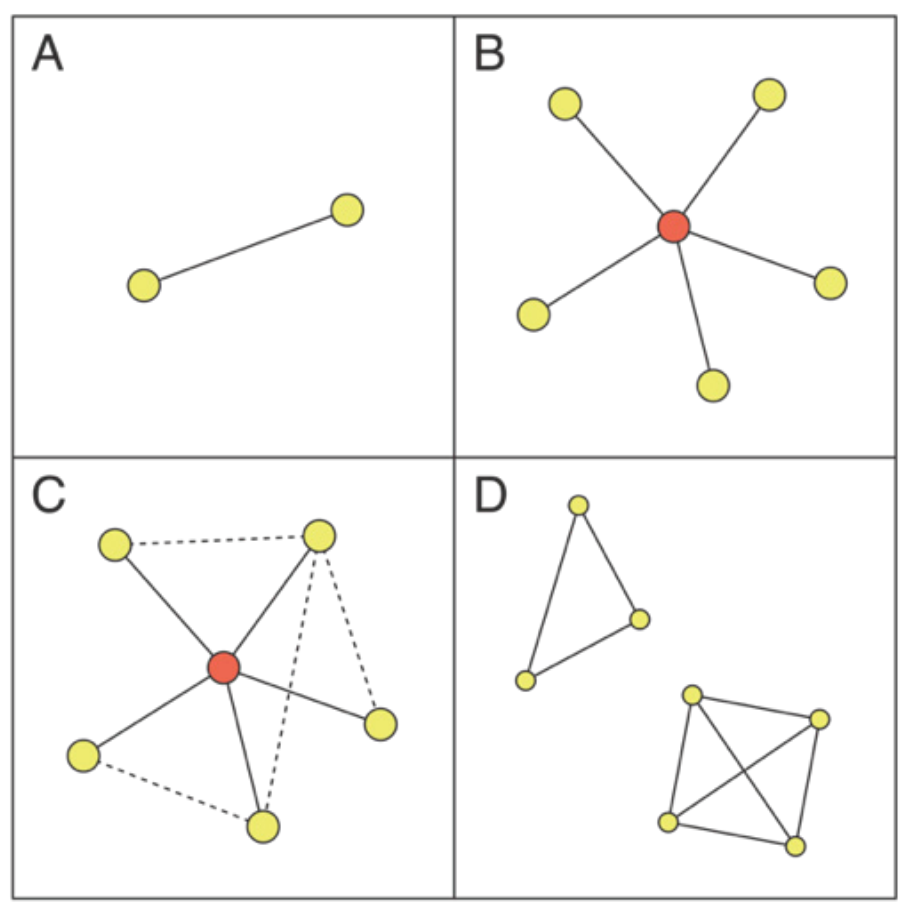

Source: Shakya et al. 2017a.

knowledge of behaviors that elicit either positive or negative sanctions. Patterns of influence may vary based on factors such as strength of social ties, hierarchies of authority, and social status and roles.

\section{BASIC CONCEPTS IN NETWORK ANALYSIS}

A social network study characterizes the web of social relations around an individual. The simplest form of a network is a social dyad (e.g., two spouses, two siblings, two friends, two neighbors). However, the network under study can be expanded to any size in which meaningful ties among the included individuals can be reliably measured.

Figure 1 illustrates some fundamental concepts about social networks. As shown in panel A, networks can be visualized by representing individuals as nodes, and connected individuals as ties; these are the fundamental building blocks of networks. The ties represent individuals who interact in some manner, and it is the patterns of social interaction that are of interest in network studies. Panel B illustrates the degree of a node, which is a metric that quantifies the number of connections (acquaintances, friends, etc.) for a 
FIGURE 2. ILLUSTRATION OF NETWORK SAMPLING. The left panel shows a network obtained through egocentric sampling. An egocentric sample consists of a set of sampled "egos" shown as red nodes (the individuals whose characteristics are being studied) and a set of "alters" shown as yellow nodes (the individuals who were nominated by the egos). Only egoalter ties and some (typically very few, if any) ego-ego ties are observed in an egocentric study, leaving all alter-alter ties outside the sample (excluded nodes shown in gray). In contrast, a sociocentric study design, shown on the right, involves obtaining network data from an entire community.
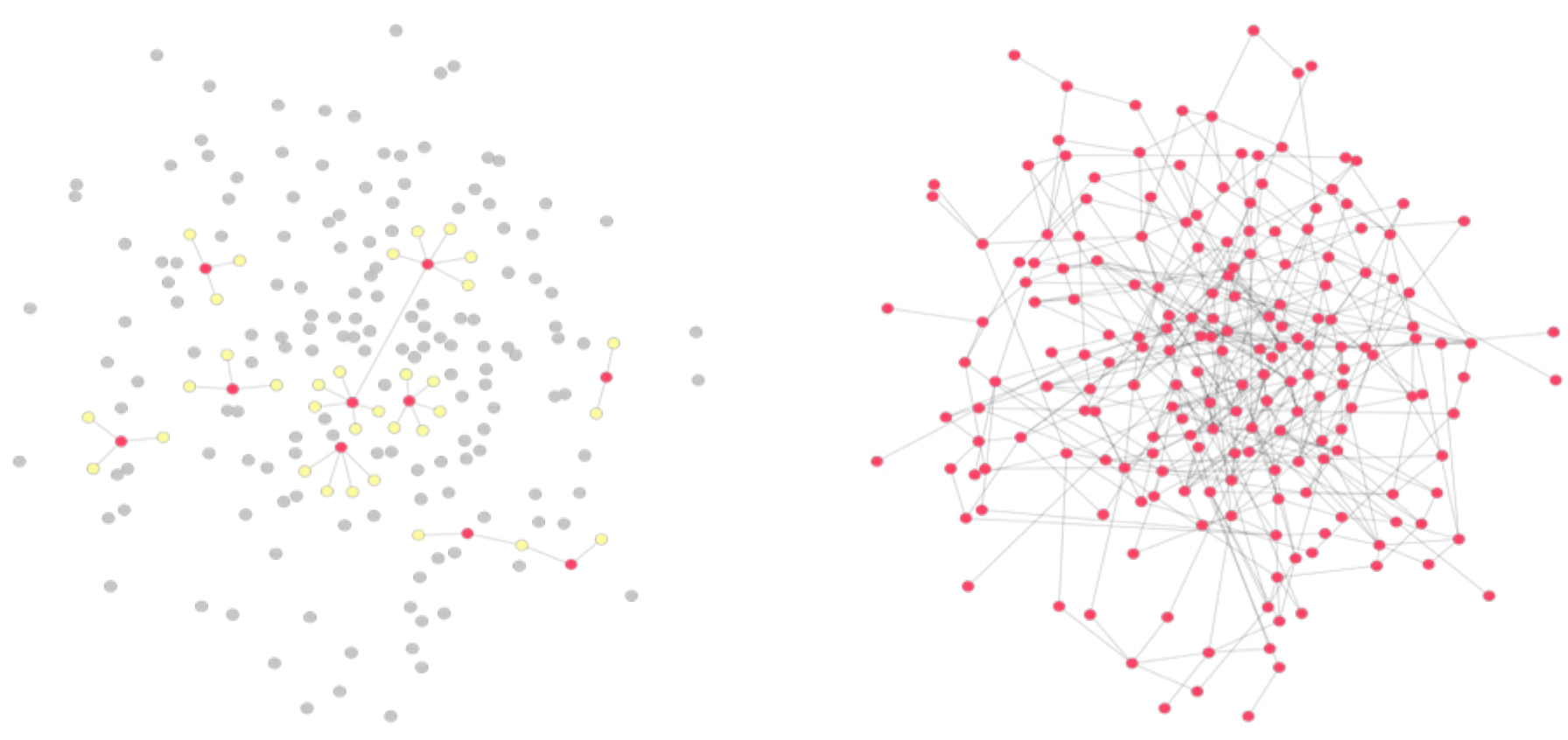

Source: Shakya et al. 2017a.

given node. For example, the red node at the center of the figure has a degree of five. The interviewee who provides this information is referred to as ego, and the people named as social contacts are alters. Panel $\mathrm{C}$ shows the connections between alters, also known as the density. In some cases, few alters are acquainted with one another, and in other instances many alters are connected to one another. Panel D shows that social networks typically possess meaningful structure beyond the level of nodes and ties. So- called "cliques" are typical examples of such structure.

Network surveys or interviews commonly ask respondents (egos) to name people with whom they have an interaction. These questions are called name generator questions (Shakya, Christakis, and Fowler 2017). The ties elicited by the name generator questions provide information on the composition and structure of the network. These questions take different forms, depending on the focus of the research. Shakya categorizes name generators as exchange questions (with whom do you borrow items or lend money?), role relation questions (friends, spouse, or other specific relationships), interactive questions (with whom do you interact during the day?), or affective (who are the people to whom you feel close? Or, with whom do you discuss important matters?) (Shakya, Christakis, and Fowler 2017). To elicit a comprehensive list of network partners, some researchers use multiple name generators. Another approach is to ask participants qualifying questions about each individual they have named, for instance, how close they are, or how often they interact. However, the decision to ask multiple name generator questions or qualifying questions must be weighed against time and resources to collect such data, as well as the focus of the study (Shakya, Christakis, and Fowler 2017).

\section{QUANTITATIVE APPROACHES}

There are two basic approaches to the collection of quantitative social network data: egocentric and sociocentric studies, illustrated in Figure 2. Egocentric studies often involve the collection of survey data from a sample of individuals within a given population (Marin and Hampton 2007; Marsden 2005) (left panel). The ties (edges) are 
reported by a selected respondent (ego) with individuals (alters) they identify in response to the name generator questions. The ties between any ego and alter in the survey are independent of the ties enumerated by other egos, and there is not necessarily any connection between one person's ties and another's. In an egocentric study, all the information regarding alters is reported by egos. Hence, these studies report the respondent's perception of factors such as the strength of ties with or preferences or behaviors of network partners. Because egocentric network data are the easiest to collect, and because it is easier to get population-representative samples in such studies, most social network studies are egocentric in nature. Sociocentric network studies (also called full network studies) create an image of a collective whole, with comprehensive data gathered on ties between all the people within a specified population (Marin and Hampton 2007; Marsden 2005). Sociocentric network studies are able to most comprehensively provide information on the network structure and the reciprocal nature of ties, as well as less biased assessments of the behavioral and attitudinal differences between the ego and their alter.

We consider these approaches quantitatively because generally there are often a large number of egos interviewed, network questions are typically asked in conjunction with pertinent attitudinal and behavioral questions, and the data are analyzed using mathematical algorithms. While this approach provides important insight into network structure, and allows for statistical inferences, it lacks the nuanced and contextual findings that are possible with qualitative approaches.

\section{QUALITATIVE APPROACHES}

Insights on how social interactions influence behavior may be obtained through qualitative network methods, following a tradition with deep roots in the discipline of anthropology. Ethnographic network mapping can be used to describe the constellation of decisionmakers, how people define themselves in relation to other decisionmakers, lines of authority, and the nature and relationship of social network partners (Knox, Savage, and Harvey 2006; Trotter II, 1999). "The advantage of ethnographic description is that it can discover behavioral details and patterns of communication and influence specific to the group" (Trotter II, 1999, p. 16). This information can illuminate the arenas of social interaction that shape or enforce social norms, as well as the composition of network partners, patterns of influence, and the enforcement of social norms that uphold or challenge prevailing practices. This approach lends itself to examining behavior at multiple levels: the preferences and actions of each individual; composition and characteristics of the proximal decisionmaking group, including the range of positions, degree of consensus, and patterns and level of influence of members; and within the community, the web of interactions, key channels of influence, and patterns of change.

Unstructured ethnographic interviews, in-depth semistructured interviews, and problem-centered interviews are the methodological approaches upon which network analysis was first conceived, and continue to be used in current qualitative and mixed methods studies (e.g., Bernardi 2004; Bernardi, Keim, and von der Lippe 2007; Dominguez and Watkins 2003; Edwards 2010; Hollstein and Wagemann 2014; Keim, Klarner, and Bernardi 2009; Molina, MayaJariego, and McCarty 2014). A set of methods have been developed for enhancing ethnographic network interviews by creating visual depictions of the social network, or sociograms, at the data-gathering stage (Hogan, Carrasco, and Wellman 2007). They are a participatory activity between the interviewer and respondent that serves to facilitate a discussion about issues such as the salient social interactions, the manner and contexts in which network partners are linked, the ways in which social influence and support are experienced, and perceptions of power and authority. In addition, the sociograms can guide deeper discussions, such as those on the meanings that individuals ascribe to these interactions.

Sociogram-aided interviewing has been adopted using both high and low technology approaches. The high-technology approach, used most often in laboratory settings in highincome countries, involves computer-aided visualization that is created in real time during the interview process (McCarty and Govindaramanujam 2005; Molina, MayaJariego, and McCarty 2014). The low-technology approach includes props and paper-based methods, frequently used in field settings where internet and electricity are often not available. In her study of friendship networks in urban areas of Cameroon, Fitzgerald wrote names of alters on chips and asked respondents to place them on a table in rows representing closeness of their relationship. Individuals in the same row were then ranked (Fitzgerald 1978, cited in Hogan, Carrasco, and Wellman 2007). Antonucci (1986) developed a hierarchical mapping technique that has been adapted in numerous qualitative studies. This method involved creating a list of alters with general name generators. 
FIGURE 3. HIERARCHICAL MAPPING SOCIOGRAM.

Names of alters nominated by ego are placed within or outside concentric circles to represent ego's perceived closeness to each alter.

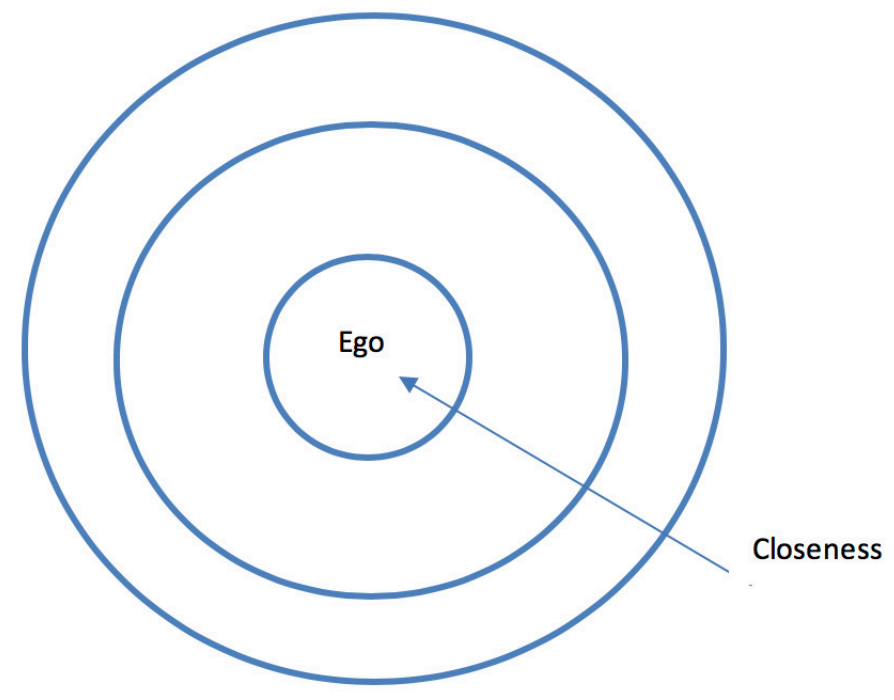

Names were then written on Post-it Notes, and respondents were asked to place each alter on a paper with concentric circles representing the respondent's perceived closeness to each network partner (see Figure 3). This sociogram guided the discussion and produced a detailed narrative of social interactions and social support (Antonucci 1986). Variants of this approach have included altering the number of concentric circles (e.g., [Hogan, Carrasoc, and Wellman 2007; Hollstein and Wagemann 2014; Keim, Klarner, and Bernardi 2009]), having the circles represent "relevance of the network partner" (Keim, Klarner, and Bernardi 2009, p. 893), subdividing the circles into "pies" that represent different domains of interaction (Haussling 2014), and clustering alters into cliques (Hogan et al. 2007). During the analytical process, Hogan and colleagues encoded their data into a network visualization software, produced network maps, and computed quantitative network metrics (Hogan, Carrasco, and Wellman 2007), forming one type of "conversion design" in which qualitative data are used to extract numeric data (Hollstein 2014; Hollstein and Wagemann 2014; Tashakkori and Teddlie 2009).

A different visual sociogram approach for interactive participatory interviewing involves the use of the Net-Map interview-based mapping tool that was developed and used for understanding the influence of social networks on strategic planning for community development, and monitoring and evaluation (Schiffer 2007). This is a paperbased technique that involves eliciting questions about
FIGURE 4. PARTICIPANT-AIDED NETWORK MAP. The ego's name is placed in the center, and the name of each alter is written on pink to designate decisionmakers or green to indicate core influencers. Round blocks identify women, and square blocks identify men. The number of chips stacked beneath the block indicate the level of influence the ego attributes to each alter. The top chip is red-side-up if alter is thought to want FGM/C to stop, and white-side-up if they are thought to prefer the continuation FGM/C. Colored lines signify types of social support, and arrows indicate the direction of flow of support.

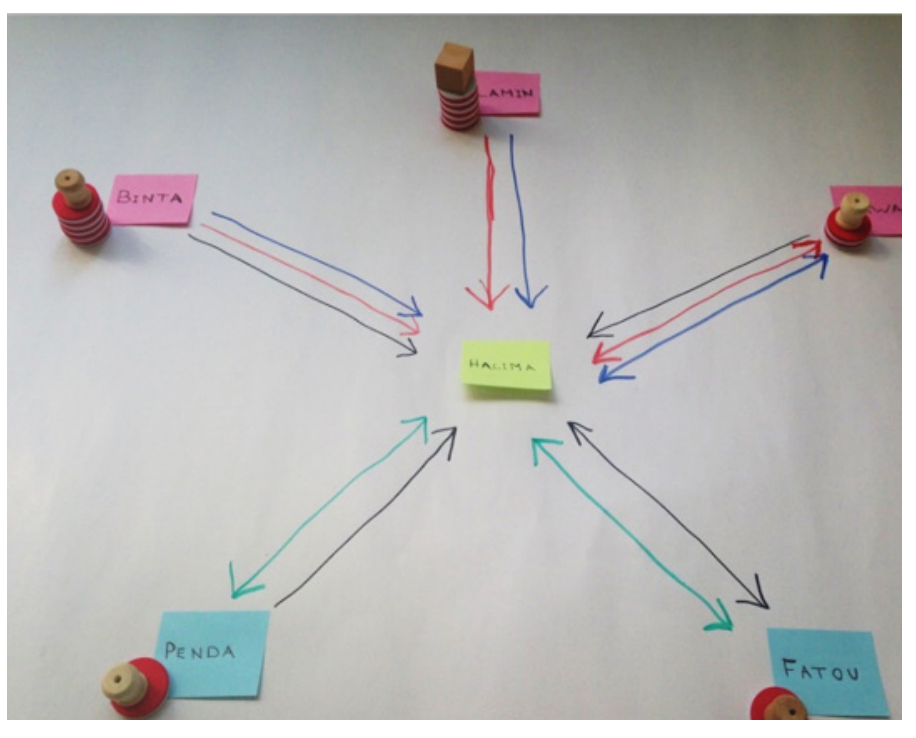

network partners and placing the names of each alter on a Post-It on a blank piece of paper. The interviewee is then asked to indicate whether each network partner supports the development goal and draws arrows between alters to indicate the flow of information or support for achieving that goal. Finally, the degree of influence of each alter is visually designated by stacking disks to represent a tower of influence (Schiffer 2007).

We adapted this approach for the study of social networks influencing decisionmaking regarding FGM/C in Senegal. Our modifications involved developing a series of generalized name generator questions to elicit names of network partners. We then narrowed this list to identify the reference group relevant to decisions regarding the care of young girls. Our prior interviews indicated that FGM/C is considered to be a matter of proper rearing of young girls. Thus, the salient referents were those who influence decisions on important matters regarding the well-being of young girls. Another modification involved specifying the type of social support, if any, between ego and each alter (with alter's 

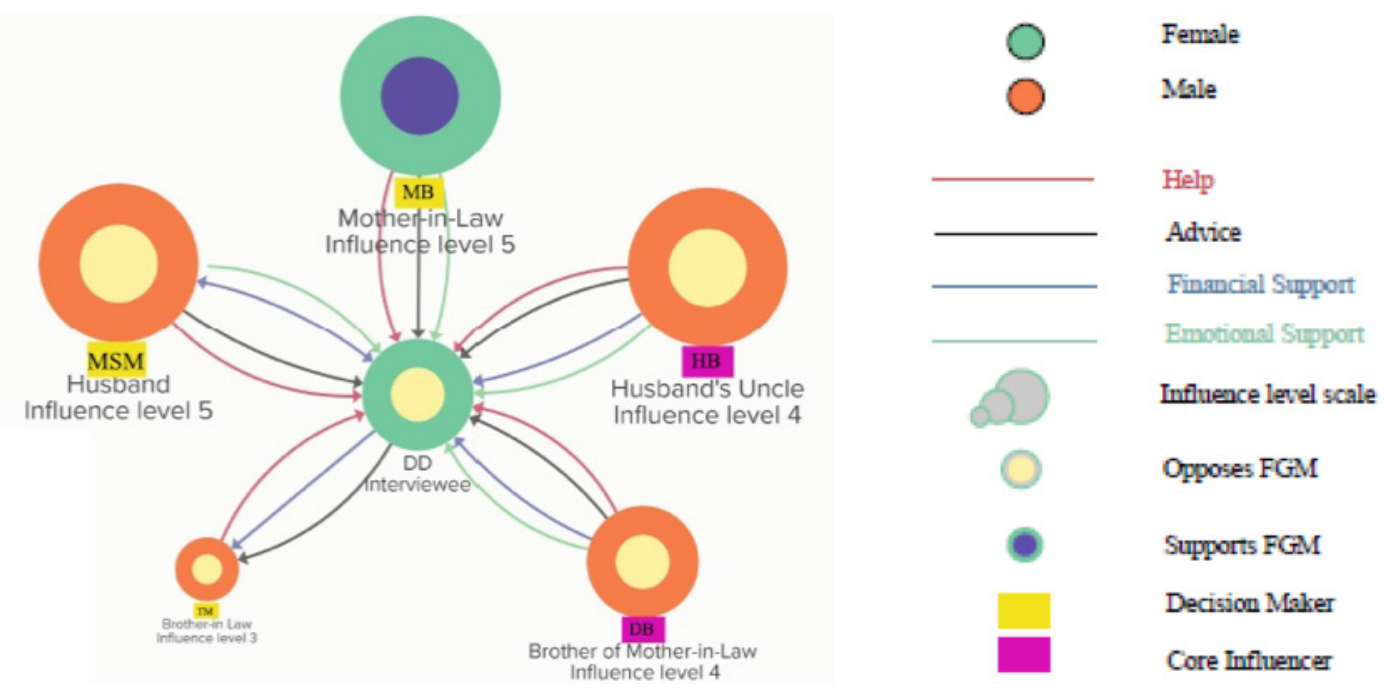

gender indicated with a round wooden block if the person is female, and a square block if the person is male). Types of support were classified as financial support, material support (help), emotional support, and informational support (advice). Additionally, alters were designated as either decisionmakers (those people the ego identifies as participating in decisions affecting the well-being of girls [using pink Post-it Notes]) or core influencers (those not participating in decisions about the well-being of girls, but who influence the decisions made [using blue Post-it Notes]) (Figure 4).

As in the original Net-Map model, arrows were drawn to indicate the direction of the flow of support, and a tower of influence was created for each alter. Chips were red-sideup if the informant believed the alter preferred for FGM/C to stop, and white-side-up if they believed the alter preferred $\mathrm{FGM} / \mathrm{C}$ to continue.

A final modification involved snowball sampling, selecting up to two alters with high influence for further interview following methods employed by Bernardi and colleagues in their study of influences on family formation in Germany (Bernardi, Keim, and von der Lippe 2007). At the end of the interview, the completed individual and combined network maps were photographed, and later digitized and anonymized, as shown in Figure 5. Details of our protocol and instruments are provided in the appendices. This protocol has been adapted by Cislaghi and colleagues to study social network influences on child marriage in Cameroon (Cislaghi, Mackie, and Shakya forthcoming).

\section{HOW DOES SOCIAL NETWORK ANALYSIS OF FGM/C RELATE TO THEORY ON BEHAVIOR CHANGE?}

A significant body of academic research has focused on the development of theoretical models of behavior change that may afford insights on the dynamics of change in norms and practices. These models fall broadly under two main paradigms: 1) individual-centered decision-theoretic models, and 2) relational models that account for the influence of interactions with others within one's social networks. Most individual-centered models of behavior rest on the assumption that there is a direct link between an individual's knowledge of the consequences of their behavior and intention to perform the behavior (Mumtaz and Salway 2009). Additionally, they posit direct links between preference, intention, and actual behavior, assuming that individuals are autonomous decisionmakers (Figure 6). Individually oriented, decision-theoretic models rest on the assumption that individuals can autonomously act upon their intentions. Hence, interventions aim to alter a person's knowledge and preferences, assuming they will motivate their intentions to change their behavior. This, in turn, is assumed to be followed by actual implementation of such behavior change (Shell-Duncan and Hernlund 2006; Yoder 2001). Within the field of health behavior, this has been dubbed the "individualist fallacy" - that is, incorrectly assuming that individuals can and do have control over their own behavior and overlooking the social context in which decisions are made (Davies and Project SIGMA 
FIGURE 6. INDIVIDUAL-CENTERED MODEL OF BEHAVIOR. Decisionmaking is linear, with knowledge influencing preferences, altered preferences sparking an intention to change, and intention to change leading to actual behavior change.

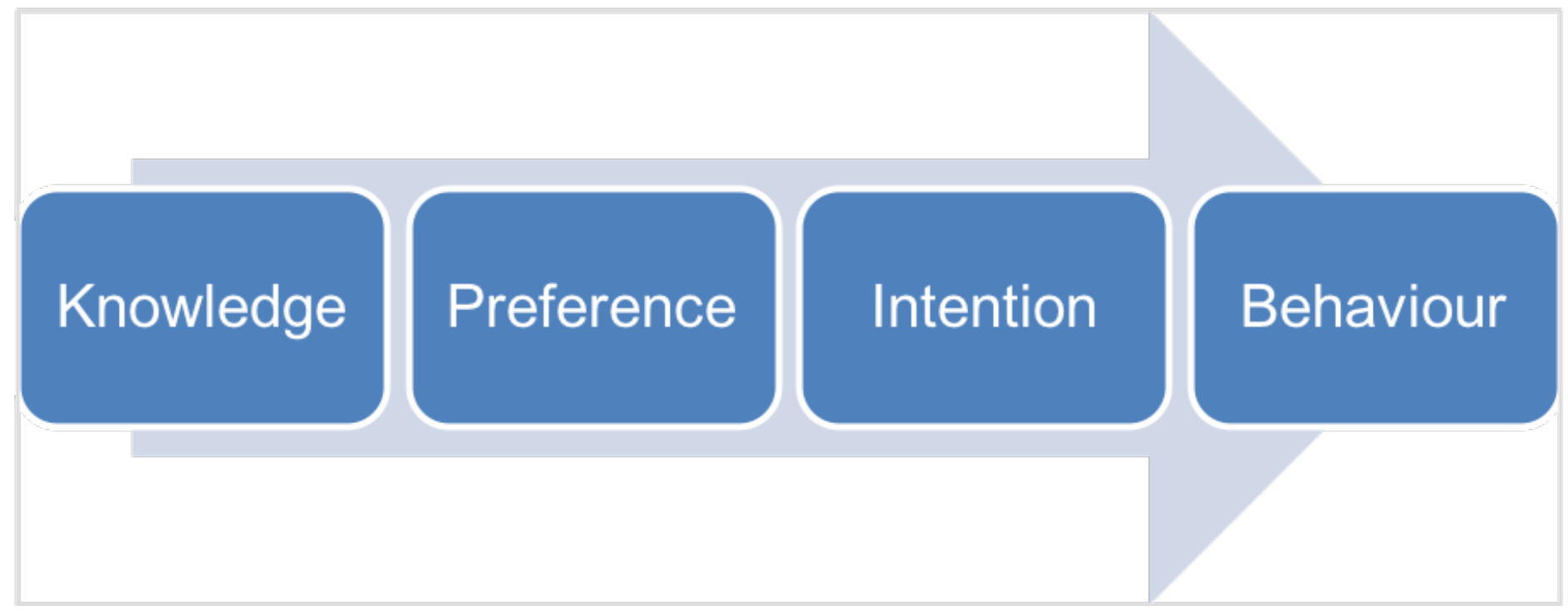

1992). Instead, research reveals that people often do not make decisions in isolation and highlights the importance of understanding the interactions of decisionmakers and the context in which decisions are made (Davies and Project SIGMA, 1992; Shell-Duncan and Hernlund 2006). Aubel (2011) argues that in many non-Western societies, decisions more broadly regarding child health and nutrition issues are rarely made independently by young mothers. Instead, Aubel's extensive literature review reveals throughout nonWestern, collectivist societies, that extended families are more prevalent, and can afford multigenerational childcare systems. She finds that childcare networks are typically organized along age and gender lines, and that age and experience of network members determine, to a great extent, their degree of influence in decisionmaking (Aubel 2011). This implies that interventions on child health, including those on FGM/C, should broaden to focus beyond individual mothers, and target the multiple, interconnected members of childcare networks.

\section{WHAT IS THE LINK BETWEEN SOCIAL NORMS THEORY AND SOCIAL NETWORK ANALYSIS?}

The first answer to this question is to note that SNA is a method, and not a theory. Social norms theory recognizes that beliefs and practices are often influenced by interactions with interconnected individuals. Social network analysis identifies the conduits through which social learning and influence occur. It identifies the salient interactions that shape social learning of norms and exert social influence on upholding or altering norms.

Recognizing the limitations of individually oriented behavior change models, scholars have turned to models that are relational, taking into account the influence of social interactions. This has led to a growing body of scholarship on the topic of social norms. This work is focused on the idea that individuals' attitudes and behaviors are often shaped and influenced by their understandings of the attitudes and practices of those people around them (Cialdini, Kallgren, and Reno 1991). The study of social norms has been undertaken by scholars in numerous fields, including sociology, social psychology, communications, public health, philosophy, and economics. While there are differences in the definition of terminology, social norms are generally understood to be behaviors that are influenced by unwritten rules regarding what is acceptable in a social group. Scholars generally define social norms as including two types of social beliefs: 1) one's own beliefs about what others in a social group do (labeled descriptive norms by Cialdini and colleagues and empirical associations by Bicchieri), and 2) beliefs about what others in the group approve or disapprove of (referred to as injunctive norms by Cialdini and colleagues, and as normative expectations by Bicchieri) (Bicchieri 2005; Cialdini, Kallgren, and Reno 1991). Thus, they include social 
practices that are actively enforced by informal positive and/or negative sanctions, such as acceptance, esteem, and approval, or avoidance, ostracism, and disapproval. Additionally, moral norms rest on internalized values of right and wrong and enforce conformity emotions such as dishonor (Boyd and Richerson 1992; Fessler 2004), while legal norms impose external sanctions, in this case through formally stated laws and punishments for violation (Mackie et al. 2015). Mackie and LeJeune (2009) argue that social customs may be maintained simultaneously by social, moral, religious, and legal norms, and emphasize that effective programming must consider this broader array of associated normative factors.

Equally important is a careful understanding of membership of the salient social group-often referred to as the reference group. This can include people with whom individuals have daily close interactions, as well as people who are more distantly or indirectly related, constituting "other people" whose expectations and anticipated approval or disapproval can influence the preferences and decisions of individuals or groups. Reference group members may include people from a variety of social circles such as close friends and family, residents of one's community, peers from school, work colleagues, and fellow members of a church or mosque. Additionally, different social norms may be influenced by different reference groups. As Mackie et al. explain, "A social norm is held in place by reciprocal expectations in a reference group. A reference group is those people whose expectations matter to a given individual in the situation, those to whom the individual refers; such an individual is called a referent by some analysts" (2015, p. 11) Hence, an individual's actions are not driven solely by their preferences and attitudes; they are also influenced by perceived expectations of others and shaped by pressure to conform. Mackie et al. emphasize that, "interdependent beliefs and actions within a social group means that social norms can be quite resistant to change and can persist even among those who would rather not follow the norm" (ibid.).

The growing focus on social norms perspectives has generated interest in understanding how to identify social norms, as well as the salient social reference group. Analysts have focused on developing effective ways of empirically identifying social norms and examining change in social norms (Mackie et al. 2015; Shell-Duncan et al. 2018). Qualitative and quantitative approaches have both been used in the process of investigating social norms and dynamics of change. Less attention has been given to understanding the social networks in which norms are embedded, as well as the structural factors that influence these networks. This involves identifying the interactions that are relevant for upholding or shaping a particular behavior, thereby constituting the reference group. Some studies on social norm change have been conducted in settings where a reference group is clearly distinguished: women's credit associations (Valente et al. 1997), schools (Paluck and Shepherd 2012), and coworkers at a polar research station (Johnson, Boster, and Palinkas 2003). In many settings where health promotion activities unfold, the salient reference group is less obvious, and research is required to identify either categories of people or specific individuals who comprise the reference group.

\section{Qualitative network analysis is a powerful approach to identifying salient social referents. It can provide critical information on the social interactions that are most influential on the formation, enforcement and possible change in social norms. Such information makes it possible to design targeted network interventions that can be used to optimize behavior change efforts.}

\section{FURTHER RESOURCES}

Readers who would like an extended introduction to social network methods are encouraged to read one of the many excellent books on this subject. We recommend:

Valente, Thomas. 2010. Social Networks and Health: Models, Methods and Applications. New York: Oxford University Press.

Readers seeking information about the analysis of qualitative network data and mixed methods in SNA are referred to the following book:

Dominguez, Silvia and Betina Hollstein. 2014. Mixed Methods Social Networks Research: Design and Applications. New York: Cambridge University Press. 
ETHNOGRAPHIC NETWORK DATA COLLECTION PROTOCOL AND PRETESTING IN THE STUDY ENTITLED "TRACING CHANGE IN FEMALE GENITAL MUTILATION/CUTTING IN SENEGAL"

\section{Study Goals and Objectives}

The goal of this study was to explore gender roles in FGM/C decisionmaking in select communities in Senegal. It sought to provide new evidence on gender roles in FGM/C shift, decisionmaking, and abandonment, and gain an improved understanding of the individual attributes and social network characteristics that potentially influence the decisionmaking process regarding $\mathrm{FGM} / \mathrm{C}$ and can shape or alter the dynamics of change.

\section{Objectives}

1. To investigate the decisionmaking process regarding continuation, change, or abandonment of the practice of $\mathrm{FGM} / \mathrm{C}$.

2. To identify interdependent social norms, including gender norms, that serve to uphold or challenge the practice of $\mathrm{FGM} / \mathrm{C}$, and the means by which these norms are enforced or contested.

3. To assess the nature, influence, and importance of interactions among social network members in deciding whether to uphold, alter, or abandon the practice of FGM/C, and identify when and how men are involved in these networks.

4. To identify the elder women and men who potentially occupy positions as influential leaders, and trace pathdependent networks through which their influence may operate.

5. To understand whether and how a gendered and intergenerational approach to FGM/C intervention strategies might optimize effectiveness.

The study took place in four select communities, two from a low $\mathrm{FGM} / \mathrm{C}$ prevalence, ethnically mixed region in central Senegal, and two from a high FGM/C prevalence, ethnically homogenous region in southern Senegal. It employed a mixed-method approach using qualitative SNA to identify connections between specific actors within a larger social structure. This approach was complemented by key informant interviews and focus group discussions to identify norms surrounding the practice of FGM/C.

Network interviews were designed to illuminate not only how people are personally connected, but also the degree to which these specific connections impact decisions
TIPS FOR FUTURE QUALITATIVE NETWORK RESEARCH (NAME GENERATORS)

1. The number of name generator questions can be quite small (not more than 2-3 questions) but need to be selected carefully.

2. The number of seed informant interviews can also be quite small (no more than 3-4 per study community), depending on the purpose of the study.

concerning the care of young girls and decisions regarding FGM/C. A total of 40 mothers were selected to participate in these ethnographic network interviews. Those identified by mothers as influential in decisionmaking concerning their daughters were then interviewed and network maps were created, providing a highly informative overview of social interactions, roles, and responsibilities of network partners, as well as their patterns and level of influence. A total of 93 interviews and network maps were completed, forming 40 cases, each one providing important information regarding views on $\mathrm{FGM} / \mathrm{C}$ in the community it described.

It is important to note that this was an exploratory study regarding the usefulness of qualitative social network methods to illuminate the network dynamics surrounding FGM/C. Because of uncertainty regarding the choice of name generators, we used many name generator questions to allow us to compare and assess which questions were most useful. We also explored how many interviews are needed to provide a meaningful understanding of network dynamics. Based on our findings, we offer two recommendations for future qualitative network research: 1) the number of name generator questions can be quite small (not more than 2-3 questions) but need to be selected carefully, and 2) depending on the nature of the study, the number of seed informant interviews can also be quite small (no more than 3-4 per study community).

\section{QUALITATIVE NETWORK INTERVIEW METHODS}

We used qualitative social network interviews to describe the constellation of decisionmakers, how people define themselves in relation to other decisionmakers, lines of authority, and the nature and relationship of social network partners. The interview protocol included the creation of a participant-aided social network map, also known as a sociogram. The interview was audio recorded, transcribed, and translated. The sociogram was photographed, and then 
digitized and anonymized. Both the interview transcript and the sociogram were used in the process of data analysis.

\section{SAMPLING}

We used snowball methodology to recruit community members to participate in ethnographic network interviews regarding key sources of influence over their opinions and decisions regarding $\mathrm{FGM} / \mathrm{C}$ and related childcare practices. A total of 40 mothers, 10 per community, were selected, along with up to two influential network partners. Mothers of girls between the ages of three months and five years who come from families that practice $\mathrm{FGM} / \mathrm{C}$ served as "seed" informants for the ethnographic network interviews. These mothers were asked to provide information on their preferences and behavior with regard to FGM/C and associated infant care practices. They were asked to identify people with whom they discuss child health or parenting and childcare more generally (people with whom they have discussed childcare, with whom they have sought advice or help, or those who have offered advice or help), and other people in their community who influence their decisions.

\section{MATERIALS}

Guidelines for interviews:

- Guidelines for interviews with mothers (Appendix 1)

- Guidelines for interviews with influential person nominated by the mother (Appendix 2)

Data collection forms:

- $\quad$ Network partner name generator form (Appendix 3)

- Decisionmaker and core influencer survey form (Appendix 4)

Network density grid (Appendix 5)—supplies for network mapping exercise:

- 1 sheet of large blank chart paper

- 3 different-colored, small Post-it Note pads

- 4 different-colored markers

- Small blocks in two shapes-square and round

- Plastic chips with a different color on each side

Recording supplies:

- Digital audio recorders

- Digital camera

\section{INTERVIEW PROTOCOL}

Interviews were conducted with an initial "seed" informant, the ego (a mother of a young girl). Interviews were also conducted with one to two influential alters named by the mother. In these interviews, the influential network partner named by the mother became the ego. Guidelines for the interviews are provided in Appendices 1 and 2 (instructions are provided in Appendix 6). General name generator questions were used to compile a "network partner" list. This list was then narrowed down to identity two categories of people:

1. Decisionmakers regarding the daughter, and

2. Core influencers (up to 5 people with most influence).

Details of the interaction were used to determine whether the information involved the following types of social support:

1. exchange of information or advice,

2. providing direct care,

3. offering or requesting material support, or

4. offering emotional support.

This information was then used to create a participatory network map, modifying methods used in the NetMap Interview Tool, which was developed and used for understanding the influence of social networks on strategic planning for community development. Network maps were photographed, and later digitized and anonymized.

Our methodology for eliciting qualitative data on social interactions involved a series of interview steps designed to identify generalized network members with strong or close ties, followed by more focused questions on those who participate in or influence care of children (especially young girls). This was followed by a series of questions on various types of social support. We describe this as a telescoping methodology, beginning with: 1) generalized interactions to identify network partners 2) interactions focused on care of young children (decisionmakers or influential persons), 3) identification of the nature of involvement in care of young girls (via questions on different forms of social support), and finally 4) attributes of the network partners, including personal family history regarding $\mathrm{FGM} / \mathrm{C}$, perceived support for the continuation of $\mathrm{FGM} / \mathrm{C}$, and perceptions regarding the law banning $\mathrm{FGM} / \mathrm{C}$.

To understand the role and relationship of network partners involved in the care of young girls, we created a sociogram, a visual representation of the networks of care. For those involved in decisionmaking or considered influential in 


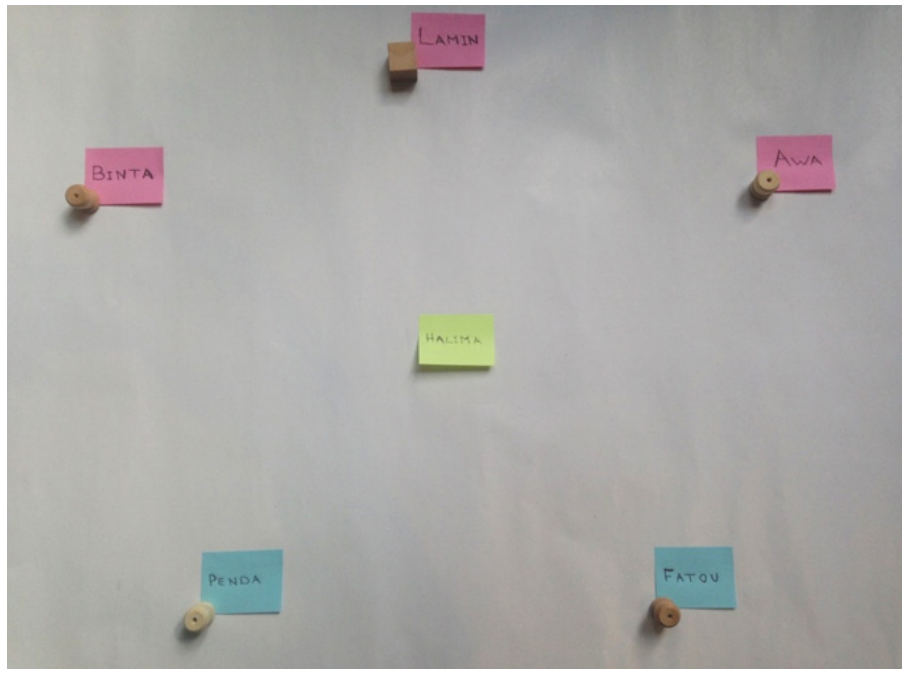

the care for girls, questions were asked about the support given in several categories: advice, emotional support, direct care or help, and financial support. This served as a springboard for deeper conversations about the nature of social interactions with respect to care for young girls, and then about the informant's perception of network partners' opinions on the continuation of FGM/C. This differs from survey methodologies that inquire about participants in direct decisionmaking about excision, as network theory suggests that decisions made by individuals or groups of individuals are influenced by their perceptions of what others in their network expect (that is, social influence). Indeed, it is important to recall that network studies on other health behaviors have found that perceptions of network partners' preferences are often more important than an individual's own preference in guiding decisionmaking. Thus, we chose to focus not only on the decisionmaking group, but the respondents' more generalized social network involved in the care of girls.

\section{MAPPING PROTOCOL}

The purpose of this mapping tool is to stimulate deeper reflection on social interactions and influence. The steps in this mapping exercise are as follows:

1. Identify decisionmakers and core influencers on matters regarding the well-being of young girls. Write the name of the ego (the interviewee), decisionmakers, and core influencers on different-colored Post-it Notes.

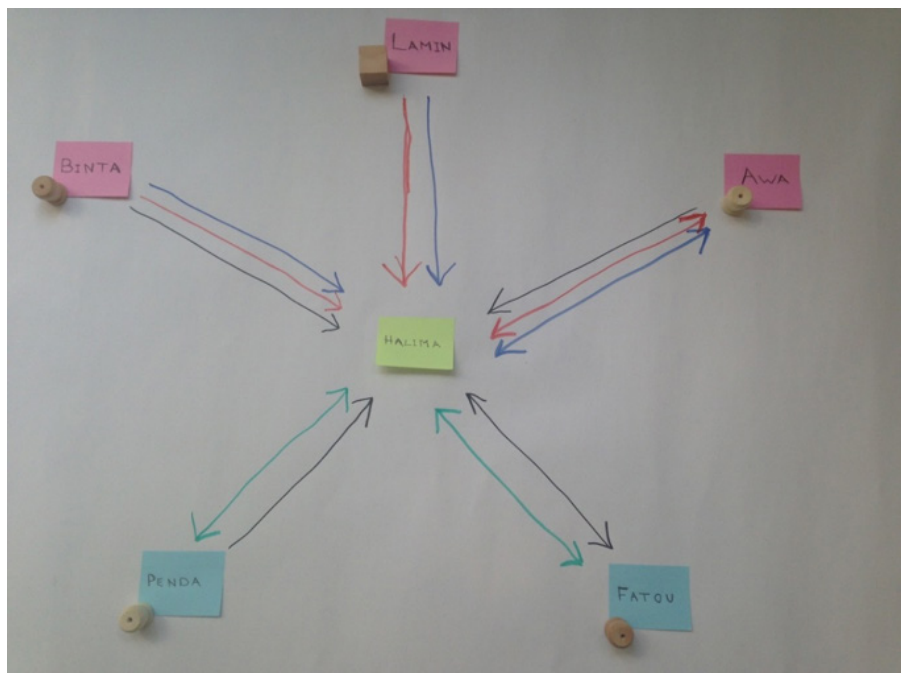

2. Place Post-it Notes with names on the blank chart paper. Next to each name, place a round wooden block if the person is a female, and a square block if the person is male.

3. Links were drawn by asking about four categories of support received from or given to each alter: a) advice, b) emotional support, c) instrumental support or help and, d) financial support. Colors indicated the general type of support (information in black, emotional support in green, instrumental support or help in red, and financial support in blue). Arrows were drawn (reflecting the direction of advice or support) between actor cards according to interviewees' directions. Arrows could be one way, or bi-directional, depending on descriptions of interviewees.

4. A tower of influence was created by asking how strongly each alter influences the interviewee. Influence ranging from 1-5 was explained to the interviewee. The interviewee was then asked to stack chips to represent the degree of influence, with higher towers representing greater influence. Towers were then placed beneath each wooden block representing an alter.

5. Discussion then took place to explain the network map and make any needed adjustments.

6. Questions were asked about the interviewees' perceptions about each network partner's views on FGM/C. The top chip was turned red-side-up if the alter was believed to oppose FGM/C, and white-side-up if the alter was believed to support FGM/C. 
FIGURE 8. STEP 3 OF MAPPING PROTOCOL

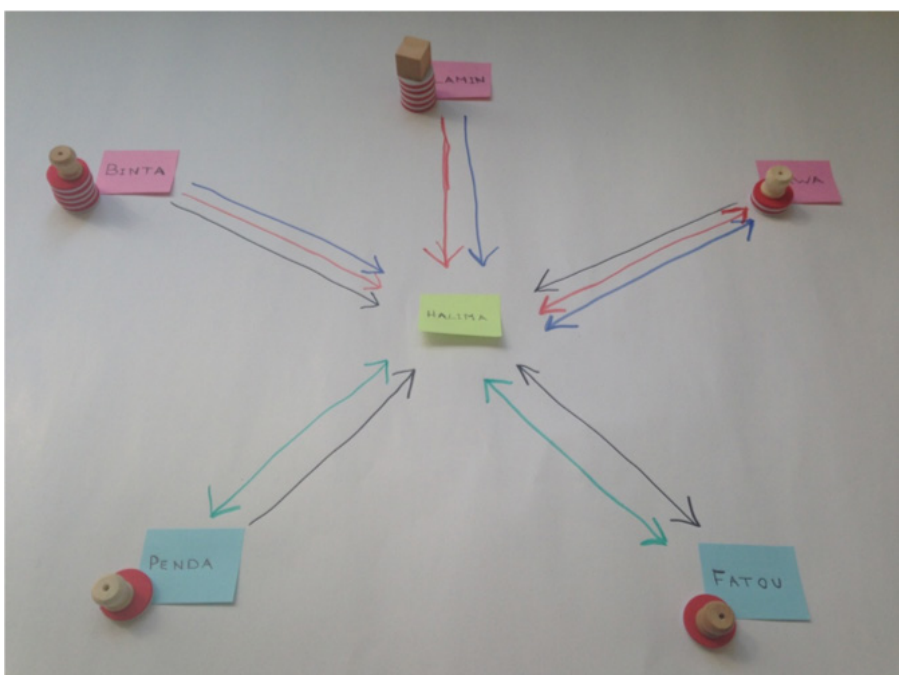

7. A network density grid was completed indicating which network partners know one another (in the view of the respondent) (Appendix 5).

8. A demographic survey form was completed for each decisionmaker and core influencer (Appendix 4).

\section{TRAINING AND PRETESTING}

\section{Training of the field team}

The training sessions introduced field team members to basic concepts in SNA, along with key concepts to be used including gender and social norms among many others. Attention was given to the use of consent forms, which were also translated into local languages during the sessions. The training covered the following:

- Introduction to basic concepts in SNA;

- Overview of ethnographic social network approaches;

- Overview of study objectives and design;

- Review of interview guidelines and data collection instruments;

- Collection of feedback from cognitive interviews from the field team, followed by reviews for flow and order of questions in the guidelines overall. This was followed by revision and refinement of guidelines and instruments;

- Review of written training protocol for social network map creation (available in Appendix 6);
- Demonstration of the protocol for qualitative network interviews and social network map creation, working in a team of two interviewers;

- Role-playing to practice network interviews and network map creation;

- Review of informed consent procedures;

- $\quad$ Preparation for pre-testing rounds;

- Debriefing following pre-tests, and guideline and instrument revisions.

\section{Pre-test of the study tools}

Our first step in pre-testing involved cognitive interviews with our field team members regarding meaning and clarity of the questions in our interview guidelines and data collection instruments. Additionally, a review of the entire interview protocol involved assessing naturalness and flow of the interview, and re-ordering questions based on this feedback.

The next step in our pre-test involved piloting our social network interview protocol among people residing in a town situated 60 miles from Dakar, the capital of Senegal. The site was selected because residents are known to have a history of having practiced FGM/C. Main tasks in the pre-test were to practice the consent procedures and qualitative network interview protocol in teams of two interviewers and assess its adequacy, refine study tools, and identify further training needs. Immediately following the interview, participants were invited to provide feedback on the interview experience. The feedback from participants and the study team members were discussed in detail the following day in a debriefing session. Specific feedback and recommendations were the following:

1. We need to have back-up digital recorders on hand, in case there are any equipment failures in the field.

2. In addition to the informed consent document that potential study participants are asked to read and sign, we need an information sheet with contact information to leave with study participants.

3. The pre-test participants found the questions to be clear, and the mapping exercise was understandable and generated rich information. For the questions on social support, we discussed whether to omit the fourth category, emotional support, but decided to keep this question.

4. It was also clarified that during the questions on tower of influence, the scale is $1-5$. If any network partner has an 
influence level of zero, they should be removed from the map.

5. Suggestions were provided by adding clarifying instructions for the mapping protocol, which were subsequently included in the training manual.

6. Suggestions were given for clarifying wording and probes throughout the interview.

7. A discussion centered on the sensitivity for doing snowball recruitment of influential network partners. It was suggested that when asking permission to contact two network partners, we repeat the segment of the consent script that describes our efforts to assure confidentiality and assure the interviewee that the information they provided will not be disclosed to anyone beyond the study team.

8. The data collection forms for ethnographic network interviews need to be stapled together in a packet in order.

9. To ease identification of proper study materials, the packets for ethnographic interview forms for mothers and for referred network partners need to be on differentcolored paper.

10. It was clarified that separate ethnographic network maps will be created during interviews with mothers and the two most influential network partners. The network partners should not be allowed to see the maps created during the interview with mothers. We also discussed the subtle ways that interview guidelines for network partners differ from those for mothers.

Based on this feedback, the proposal and study instruments were revised, and ready for translation. Further practice of the interview and mapping protocol was also deemed necessary.

A final round of pre-testing involved an undeclared pre-test using translated guidelines in a study site where people speak both Mandinka and Pulaar (the two major languages in our study sites). Interviewers made notes regarding the need to refine the language of select questions in our interview guidelines. Findings discussed during our debriefing session included the following:

1. The interview process is lengthy, and there is a concern regarding respondent burden. We noted that the interviews became faster as the field team became more practiced. We considered removing questions but decided that because of the exploratory nature of this interview protocol, all questions would be retained.
2. The protocol implemented two rounds of name generators: the first involving general questions and the second involving questions on people involved in important matters regarding the well-being of young girls. Although time-consuming, this was necessary in order to restrict the larger social network to those who are potentially important regarding decisions on FGM/C. In other words, it was an important element of defining the correct reference group.

3. The need to be aware of inconsistencies arose during this pre-test. Some participants listed individuals as both a decisionmaker and a core influencer, while other individuals may not have been mentioned in the preliminary name generator questions, yet they were noted as core influencers/decisionmakers later on in the interview, and they were not always included in the sociogram. Reminders were given to pay close attention to such details throughout the interview process.

4. The need to pay close attention to writing names and relationships became evident, particularly because of the use of multiple names, fictive kinship, and inconsistencies in different parts of the interview.

\section{LESSONS LEARNED FROM DATA COLLECTION, PROCESSING, AND ANALYSIS}

Finally, we share a set of lessons learned as we transcribed our data, created a database, and validated our data.

Richness of the data and intuitive appeal. The co-creation of a visual social network map allowed the participants to be guided into a detailed discussion of their social interactions regarding the well-being of young girls. This mapping exercise provided opportunities for respondents to reflect on their interactions with the individuals listed on their maps, elaborate on their degree of influence, and add refinements when necessary.

Identification of the reference group. Most social network studies use one or a few name generator questions to make the length of the interview manageable. The large number of name generator questions we posed to our respondents produced comprehensive lists of network partners, and was done in order to identify a limited set of best name generator questions in future studies. Shifting the conversation to the topic of well-being of girls then helped identify the salient others in their reference groups, which was only a fraction of their network partner lists. We have described this as a "telescoping" methodology. It was important to have prior knowledge that FGM/C is considered to be a matter of proper parenting, and to identify the reference groups by using 
questions that pertained to those involved with or interested in the well-being of young girls in the respondent's family.

Simplicity of a paper and prop method. The creation of a network map on paper using Post-it Notes, props (blocks with two shapes to indicate gender, and chips to create a tower of influence), and different-colored markers to indicate the type of social support and its direction was a low-technology approach that was suitable for field research. Photographing the maps made it easy to record them until they could be digitized and anonymized.

Translation concerns for interviewers and transcribers. Interviews from this study were conducted in French and several local languages, while reporting and data analysis has been done in French and English. Having local and multi-lingual team members for data collection, quality control, and data analysis has been critical to this project, particularly when understanding culturally nuanced meanings of our social network data.

\section{Observations about name generator questions that are} important when analyzing data. When analyzing social network data, it is important to know how name generator questions were interpreted in the field. The name generator question regarding "help" was not clearly worded. We wanted to know who helps with the provision of direct care for girls in the home, but with the translation of this question into several languages (French, Mandinka, Wolof, and Pulaar), it emphasized "help" and not "provision of direct care," as intended. While respondents gave emphatic "no" responses to this question, triangulation of the study data shows that men may provide supportive care when needed. This, in turn, informs the role men play within the home. Additionally, our name generator question, "Besides the people you listed, are there people in this community who you consider to be influential?" may not have accurately captured the level of influence individuals have on the community and regional level (such as people serving as community health workers). This question may have also limited the number of influential community members a respondent could nominate, if they had previously nominated them for other name generator questions. Further analysis of our name generator data will take these kinds of nuances into consideration.

Fictive kinship: Validating social network relationships. Peaceful co-existence between neighbors and community members generates trust and understanding, which may often lead to strong ties of fictive kinship. This seems to be especially true if two non-blood-related individuals share the same surname. Surnames are important in Senegal and in the West African context in general, as they signify that all people with the same surname are descendants of one common ancestor. We found that during data collection, egos and interviewed alters would at times address individuals as a sister, brother, cousin, or other family member who would not be directly related to them. During these interviewers, if the respondent further clarified their relationship to be a non-kin tie, the interviewers and quality control team would rectify the name generator list, related forms, and sociogram. During data processing, these data were also reviewed and validated again before being entered into the database.

Reporting ethnic identities. When comparing an interviewed alter's socio-demographic information as reported by their ego and vice versa, we noticed that the ethnic identity of the same individual sometimes differed depending on who reported it. We believe this was partly due to respondents' divergent perspectives on how to distinguish one's ethnic identity: an individual's ability to speak a local language versus their ethnic identity determined by patrilineal heritage and surname. Additionally, while custom dictates that ethnicity is inherited patrilineally, the reality for people of mixed heritage is often fluid across time and social contexts.

This research study, as well as other studies in similar contexts, must take into account how participants perceive and report ethnicity/ethnic group identity. Given the complexity of social ties and ethnic identities in our study sites, we will be including community profiles in further reports. These profiles will describe the history and sociocultural/ethnic makeup of these communities, to help explain the rich, contextual differences of our Central and Southern Senegal sites.

Interviewer burden. The interview process that included the creation of a sociogram required substantial interviewer training. When study tools are being piloted or are new for data collectors, it is crucial that the entire team have a comprehensive understanding of the data collection and data analysis process. This will help the field team administer the study tools and maximize quality control measures in realtime.

Respondent burden. The interview protocol adopted in this study resulted in interviews that took a great deal of time and required intense concentration from our respondents and interviewers. It is possible to streamline our interview protocol and limit the number of informants in the future, as each interview produces a voluminous amount of rich data. The interview protocol can be streamlined by reducing the number of general name generator questions, which should be limited to no more than 2-3 questions. Depending on the nature of the study, we also suggest that as few as 3-4 interviews with seed informants per study site can be enough to reach saturation on network dynamics. 


\section{REFERENCES}

Alexander, C., M. Piazza, D. Mekos, and T.W. Valente. 1987.

"Peer networks and adolescent cigarette smoking: An analysis of the national longitudinal study of adolescent health," Journal of Adolescent Health 29: 22-30.

Antonucci, T. 1986. "Measuring social support networks: Hierarchical mapping technique," Generations 10: 10-12.

Aubel, J. 2011. "The role and influence of grandmothers on child nutrition: culturally designated advisors and caregivers," Maternal and Child Nutrition 8(1): 19-35.

Barnes, J.A. (954. "Class and committee in a Norwegian island parish," Human Relations 7: 39-58.

Bauman, K. and S. Ennett. 1994. "Peer influence on adolescent drug use," American Psychologist 49: 820-822.

Behrman, J., H.-P.Kohler, and S.C. Watkins. 2002. "Social networks and changes in contraceptive use over time: Evidence from a longitudinal study in rural Kenya," Demography 39(4): 713-738.

Bernardi, L. 2004. "Channels of social influence on reproduction," Population Research and Policy Review 22: 527-555.

Bernardi, L., S. Keim, and H. von der Lippe. 2007. :Social influences on fertility: A comparative mixed methods study in Eastern and Western Germany," Journal of Mixed Methods Research 1(1): 23-47.

Bicchieri, C. 2005. The Grammar of Society: Nature and Dynamics of Social Norms. Cambridge: Cambridge University Press.

Bott, E. 1957. Family and Social Networks: Roles, Norms, and External Relationships in Ordinary Urban Families. London: Tavistock.

Boyd, R., and P. J. Richerson. 1992. "Punishment allows the evolution of cooperation (or anything else) in sizable groups," Ethnology and Sociobiology 13(3): 171-195.

Brunson, E. 2013. "The impact of social networks on parents' vaccination decisions," Pediatrics 131(5): e1397-e1404.

Buetow, S. 2005. "To care is to coprovide," Annals of Family Medicine 3(6): 553-555.

Christakis, N. and J. Fowler. 2007. "The spread of obesity in a large social network over 32 years," The New England Journal of Medicine 357: 370-379.

Cialdini, R.B., C. Kallgren, and R. Reno. 1991. "A focus theory of normative conduct: $A$ theoretical refinement and reevaluation of role of norms in human behavior," Advances in Experimental Social Psychology 24(20): 201-234.
Cislaghi, B., G. Mackie, and H. Shakya. (forthcoming). Social Norms Sustaining Child Marriage in Far North and South-East Cameroon: A Qualitative Study with Four Ethnic Groups.

Davies, P. and Project SIGMA. 1992. "On relapse: Recidivism or rational response?" in P. Aggelton, P. Davies, and G. Hart (eds.), AIDS: Rights, Risk and Reason, pp. 133-141. Washington DC: The Falmer Press.

Dominguez, S., and C. Watkins. 2003. "Creating networks for survival and mobility: Social capital among African-American and Latin-American low-income mothers," Social Problems 50(1): $111-135$.

Edwards, G. 2010. Mixed-Method Approaches to Social Network Analysis. National Centre for Research Methods Report NCRM/015. Retrieved from http://eprints.ncrm.ac.uk/842/.

Fessler, D. 2004. "Shame in two cultures: Implications for evolutionary approaches," Journal of Cognition and Culture 4(2): 207-262.

Fonseca-Becker, F. and T.W. Valente. 2006. "Promoting breastfeeding in Bolivia: Do social networks add to the predictive value of traditional socioeconomic characteristics?" Journal of Health, Population and Nutrition 24(1): 71-80.

Haussling, R. 2014. "A network analytical four-level concept for an interpretation of social interaction in terms of structure and agency," in S. Dominguez and B. Hollstein (eds.), Mixed Methods Social Networks Research: Design and Applications, pp. 90-117. New York: Cambridge University Press.

Hogan, B., J. A. Carrasco, and B. Wellman. 2007. "Visualizing personal networks: Working with participant-aided sociograms," Field Methods 19(2): 116-144.

Hollstein, B. 2014. "Mixed methods social network research: An introduction," in S. Dominguez and B. Hollstein (eds.), Mixed Methods Social Network Research, pp. 3-34.). Cambridge: Cambridge University Press.

Hollstein, B. and C. Wagemann. 2014. "Fuzzy-set analysis of network data as mixed method: Personal networks and the transition from school to work, : in S. Dominguez and B. Hollstein (eds.), Mixed Methods Social Networks Research: Design and Applications, pp. 237-268. New York: Cambridge University Press.

Johnson, J., J. S. Boster, and L. A. Palinkas. 2003. "Social roles and the evolution of networks in and extreme and isolated environment," Journal of Mathematical Sociology 27(2-3): 89-121.

Keim, S., A. Klarner, and L. Bernardi. 2009. "Qualifying social influence on fertility intentions," Current Sociology 57(6): 888-907. 
Knox, H., M. Savage, and P. Harvey. 2006. "Social networks and the study of social relations: Networks as method, metaphor and form," Economy and Society 35(1): 113-140.

Mackie, G. and J. LeJeune. 2009. Social Dynamics of Abandonment of Harmful Practices: A New Look at the Theory.

Mackie, G., F. Moneti, H. Shakya, and E. Denny. 2015. What are Social Norms? How are they Measured?

Marin, A., and K. N. Hampton. 2007. "Simplifying the personal network name generator," Field Methods 19: 163.

Marsden, P.V. 2005. "Recent developments in network measurement," in P.J. Carrington, J. Scott, and S. Wasserman (eds.), Models and Methods in Social Network Analysis. New York: Cambridge University Press.

McCarty, C. and S. Govindaramanujam. 2005. "A modified elicitation of personal networks using dynamic visualization," Connections 26(2): 61-69.

Mitchell, J.C. 1969. Social Networks in Urban Situations: Analyses of Personal Relationships in Central African Towns. Manchester: Manchester University Press.

Moestue, H., S. Huttly, L. Sarella, and S. Galab. 2007. “'The bigger the better'-Mothers' social networks and child nutrition in Andhra Pradesh," Public Health Nutrition 10(11): 1274-1282.

Molina, J.L., I. Maya-Jariego, and C. McCarty. 2014. "Giving meaning to social networks: Methodology for conducting and analyzing interviews based on personal network visualizations," in S. Dominguez and B. Hollstein (eds.), Mixed Methods Social Networks Research: Design and Applications, pp. 305-335. New York: Cambridge University Press.

Morris, M. 1997. "Sexual networks and HIV," AIDS Education and Prevention 11(suppl A): S209-S216.

Mumtaz, Z. and S. Salway. 2009. "Understanding gendered influences on women's reproductive health in Pakistan: Moving beyond the autonomy paradigm," Social Science and Medicine 68: 1349-1356.

Paluck, E. L. and H. Shepherd. 2012. "The salience of social referents: A field experiment on collective norms and harassment behavior in a school social network," Journal of Personality and Social Psychology 103(6): 899-915.

Schiffer, E. 2007. Net-Map Toolbox: Influence Mapping of Social Networks. https://netmap.wordpress.com/tag/social-networkanalysis/, accessed June 20, 2018.

Shakya, H., N. A. Christakis, and J. Fowler. 2017. "An exploratory comparison of name generator content: Data from rural India," Social Networks 48: 157-168.
Shakya, H., D. Stafford, D. A. Hughes, T. Keegan, et al. 2017a. "Exploiting social influence to magnify population-level behaviour change in maternal and child health: Study protocol for a randomized controlled trial of network targeting algorithms in rural Honduras," BMJ Open 7:e012996. doi:012910.011136/ bmjopen-012016-012996.

Shakya, H.B., C.J. Farris, C. Ojeda, A. Raj, and E. Reed. (2017b). "Sexual network clustering of sexual violence experienced by adolescent girls," American Journal of Epidemiology 186(7): 796-804. http://doi.org/710.1093/aje/ kwy1154.

Shell-Duncan, B. and Y. Hernlund. 2006. "Are there 'stages of change' in the practice of female genital cutting?: Qualitative research findings from Senegal and The Gambia," African Journal of Reproductive Health 10(2): 57-71.

Shell-Duncan, B., A. Moreau, K. Wander, and S. Smith. 2018. "The role of older women in contesting norms associated with female genital mutilation/cutting: A factorial focus group analysis," PLoS ONE 13(7): e0199217. https://doi.org/10.1371/ journal.pone.0199217

Tashakkori, A. and C. Teddlie. 2009. "Integrating qualitative and quantitative approaches to research," in L. Bickmand and D.J. Rog (eds.), Sage Handbook of Applied Social Research Methods 2nd Edition. Los Angeles: Sage Publications, Inc.

Trotter II, R.T. 1999. "Friends, relatives and relevant others: Conducting ethnographic network studies," in J. Schensul, M. LeCompte, R. T. Trotter II, E. Cromley, and M. Sinder (eds.), Mapping Social Networks, Spatial Data, and Hidden Populations. Walnut Creek, CA: AltaMira Press.

Valente, T.W. 2010. Social Networks and Health: Models, Methods, and Applications. New York: Oxford University Press.

Valente, T.W., M. Mouttapa, and M. Gallaher. 2004. "Social network analysis for understanding substance abuse: A transdisciplinary perspective," Substance Use and Misuse 39: 1685-1712.

Valente, T.W., S.C. Watkins, M.N. Jato, A. van der Straten, and L.-P. M. Tsitsol. 1997. "Social network associations with contraceptive use among Cameroonian women in voluntary associations," Social Science and Medicine 45(5): 677-687.

Yoder, P.S. 2001. "From sexual behavior to sexual encounters: Issues in AIDS prevention research," Reviews in Anthropology 30: 225-241. 


\section{INTERVIEW GUIDELINES}

\section{INDIVIDUAL MOTHERS}

Inclusion criteria:

1. Has a daughter between ages 3 months and 5 years

2. Comes from a family that once practiced excision

Obtain informed consent

Note start time:

\section{STEP 1: RESPONDENT BACKGROUND}

\subsection{Respondent's name}

1.2 Age

1.3 Ethnicity

1.4 Marital status

1.5 Ethnicity of husband

1.6 Number of children

1.7 Name of daughter under age 5

1.8 Age of daughter (the one who is between 3 months and 5 years of age)

1.9 How long has respondent lived in this community?

\section{STEP 2: NAME GENERATOR QUESTIONS}

(Instructions: The questions below should be used to complete the Network Partner Name Generator Form. For each person mentioned, obtain their name and their relationship to the respondent. Also record the number of the question that led to the mention of each name.)

\section{Affective (emotional)}

2.1 From time to time, most people discuss important matters with other people. With whom do you discuss matters that are important to you?

2.2 If you feel worried or upset, or have a problem and want to talk to someone about it, who do you talk to?

2.3 Who are the people you feel closest to in your life? (faux kin)

Instrumental support (help)

2.4 Suppose you need help with jobs around the house. Who would you ask to help you?

2.5 When you are sick or recovering, who would you ask to help you?

2.6 If you need help, such as finding transport (a ride), who might you ask for help?

2.7 Are there people who call on you when they are sick or need help? 


\section{Financial Support}

2.8 Suppose you need to borrow money. Who would you feel you could ask for money?

2.9 Are there people who come to you when they need to borrow money? Who?

\section{Information}

2.10 If you want information about an innovation, like a new technology or an illness treatment, who would you ask?

2.11 Who comes to you for information?

\section{Interaction/time}

2.12 Who are people that you spend time with in your free time?

2.13 With whom do you talk when you are out, such as at the market, or while working?

2.14 Who are people you talk to when attending groups (community meetings, groups)?

\section{Other}

2.15 Are there people you are close to who you have not mentioned yet? (probe if spouse not listed)

2.16 Besides the people you listed, are there people in this community who you consider to be influential?

\section{STEP 3: IDENTIFYING DECISIONMAKERS ON MATTERS PERTAINING TO CHILD WELL-BEING}

(Instructions: Refer back to list of network partners on the Name Generator form. Mark "D" next to people who are identified as decisionmakers ON MATTERS PERTAINING TO THE WELL-BEING OF GIRLS. There is no limit on the number of people who can be named. Use the following questions to identify decisionmakers:)

3.1 Who participates in important decisions about girls in your family?

3.2 Who decides if you should seek medical care if your daughter is sick?

3.3 When your child is older, who will help decide if and when she is ready for school?

3.4 Who participates in any other important decisions about your daughter?

\section{STEP 4: IDENTIFYING CORE INFLUENCERS ON MATTERS PERTAINING TO CHILD WELL-BEING}

(Instructions: Refer back to names listed from the name generator list. Mark the name generator list with an "l" next to the most influential people. Allow respondent to list up to 5 people. Use the following question:)

4.1 In addition to people who participate in decisionmaking, who are most influential people on your caregiving of your children? 


\section{STEP 5: CREATE THE NETWORK MAP}

(Instructions: List all decisionmakers on the network diagram on Post-it Notes. Then list up to 5 most influential persons.)

Color code: Decisionmakers $=$ pink

Core influencers $=$ blue

Respondent (ego) $=$ green

(Note: It is OK if the respondent, Ego, wants to add different decisionmakers or core influencers to the map. But there can be only 5 core influencers. If they add a 6th influential person, one must be removed. There is no maximum on decisionmakers, but the maximum number of core influencers is 5.)

\section{STEP 6: DRAW ARROWS FOR ADVICE, ASSISTANCE, AND FINANCIAL SUPPORT}

(Instructions: Next, draw arrows showing advice, help, and financial support. The arrow should show the direction of the support. The arrow can be a one-way arrow $\rightarrow$ or a two-way arrow $\leftrightarrow$.)

"I would like to know more about these people in your family and community who are concerned about the well-being of your child. We would like you to tell us about the people who are concerned about your child, and the types of concerns they have."

Advice (black lines and arrows) —I would like to ask you about people who give you advice about your child, or people you advise.

6.1 Who advises you on child feeding?

6.2 Did anyone advise you on when it was time to introduce foods other than breastmilk? Who?

6.3 Who advises you on care when your child does not feel well?

6.4 Who advises you about training your child to make sure she is well behaved?

6.5 Do people come to you for advice about their children? If yes, who?

Emotional support (green lines and arrows)—I would like to ask you about people who give you emotional support when you are worried or upset about your child.

6.6 Who gives you encouragement or emotional support when you are worried or upset about your child?

Help (red lines and arrows)—I would like to ask you about people who help you with taking care of your child, or people you help.

6.7 Who helps care for or feed your child?

6.8 Who helps treat your child when she is not well?

Financial support (blue lines and arrows)

6.9 Who helps you pay for your children's expenses when needed, or who asks you for financial help?

6.10 Who helps pay for things such as food or clothing or ceremonies?

6.11 Who helps pay for medicine?

6.12 Who helps pay for school fees?

6.13 Do you help anyone out when they need money? If yes, who? 


\section{STEP 7: TOWER OF INFLUENCE}

Stack chips to represent who has the most influence over the way you give care for your daughter (1= least influence, $5=$ most influence).

\section{STEP 8: QUESTIONS ON EXCISION}

We would like to understand more about how people in your community make decisions about excision.

8.1 I know that there are campaigns for ending excision. How do you feel about this?

8.2 Where have you been told things about excision? What did you hear?

8.3 (If formally educated): Did you hear about excision in school? (if yes,) what did you hear?

8.4 Do you think excision should be stopped? Why? Why not?

8.5 What changes have you seen in the practice over the years?

8.6 Do you yourself remember going to excision? If no, skip to question 8.14.

8.7 How old were you?

8.8 Did you go in a large group?

8.9 Did you stay in the bush or in town?

8.10 Did you stay afterwards to learn?

8.11 What sorts of things did you learn?

8.12 Was there a celebration afterwards?

8.13 Which parts of these traditions are important to keep?

8.14 What type of excision was practiced in your family? (Infibulation or other)

8.15 Is there a difference in the way that circumcised and uncircumcised women are treated?

8.16 If you have gone or not, does that have an effect on finding a husband?

8.17 Who are the people for whom the practice is most important?

8.18 Who are the people who want it to stop?

8.19 Do you know if there is a law banning excision? If no, skip to question 8.22.

8.20 What, exactly does the law say?

8.21 What is your opinion about the law? Please explain.

\section{Questions about daughter's excision}

8.22 Has your daughter been excised? If no, skip to next section.

8.23 When your daughter underwent circumcision, who decided that it was time?

8.24 Who participated in discussing the arrangements?

8.25 What issues were discussed?

8.26 Were there any disagreements?

8.27 If yes, how was the disagreement settled?

8.28 Were any medicines used? 


\section{STEP 9: QUESTIONS ON DECISIONMAKERS AND CORE INFLUENCERS}

(Instructions: Fill out one Decisionmaker and Core Influencer Survey form for each person on the network map. You should fill out one survey for each alter, but the questions are asked to ego.)

\section{STEP 10: NETWORK DENSITY GRID}

(Instructions: Use the Network Density Grid form to mark an "X" to indicate any decisionmakers and core influencers who DO NOT KNOW EACH OTHER.)

STEP 11: ASK FOR PERMISSION TO TALK TO THE TWO PEOPLE WITH THE HIGHEST INFLUENCE TOWERS (IF THEY LIVE IN THE SAME COMMUNITY)

Note interview end time:

Interviewers: Please write a debrief on your observations and thoughts about the interview. 


\section{APPENDIX 2. INTERVIEW GUIDELINES FOR INFLUENTIAL NETWORK PARTNER}

\section{INTERVIEW GUIDELINES}

\section{PEOPLE NOMINATED BY THE MOTHER WHO HAD LARGE INFLUENCE TOWERS}

(Note: in this interview they will be the new Ego)

Inclusion criteria:

1. Nominated in the interview of a mother with girls ages 3 months to 5 years

2. Live in same community

Obtain informed consent

Note start time:

\section{STEP 1: RESPONDENT BACKGROUND}

1.1 Respondent's name

1.2 Gender

1.3 Age

1.4 Ethnicity

1.5 Marital status

1.6 Ethnicity of spouse

1.7 Number of children

1.8 How long has respondent lived in this community?

1.9 Name of mother who nominated this respondent?

\section{STEP 2: NAME GENERATOR QUESTIONS}

(Instructions: The questions below should be used to complete the Network Partner Name Generator Form. For each person mentioned, obtain their name and their relationship to the respondent. Also record the number of the question that led to the mention of each name.)

\section{Affective (emotional)}

2.1 From time to time, most people discuss important matters with other people. With whom do you discuss matters that are important to you?

2.2 If you feel worried or upset, or have a problem and want to talk to someone about it, who do you talk to?

2.3 Who are the people you feel closest to in your life? (faux kin)

\section{Instrumental support (help)}

2.4 Suppose you need help with jobs around the house. Who would you ask to help you?

2.5 When you are sick or recovering, who would you ask to help you?

2.6 If you need help, such as finding transport (a ride), who might you ask for help?

2.7 Are there people who call on you when they are sick or need help? 


\section{Financial Support}

2.8 Suppose you need to borrow money. Who would you feel you could ask for money?

2.9 Are there people who come to you when they need to borrow money? Who?

Information

2.10 If you want information about an innovation, like a new technology or an illness treatment, who would you ask?

2.11 Who comes to you for information?

\section{Interaction/Time}

2.12 Who are people that you spend time with in your free time?

2.13 With whom to you talk when you are out, such as at the market, or while working?

2.14 Who are people you talk to when attending groups (e.g., community meetings)?

\section{Other}

2.15 Are there people you are close to who you have not mentioned yet? (probe if spouse not listed)

2.16 Besides the people you listed, are there people in this community who you consider to be influential?

\section{STEP 3: IDENTIFYING DECISIONMAKERS ON MATTERS PERTAINING TO CHILD WELL-BEING}

(Instructions: Refer back to list of network partners on the Name Generator form. Mark "D" next to people who are identified as decisionmakers OF MATTERS PERTAINING TO THE WELL-BEING OF GIRLS. There is no limit on the number of people who can be named. Use the following questions to identify decisionmakers:)

3.1 Who participates in important decisions about girls in your family?

3.2 Who decides if you should seek medical care if a girl in your family is sick?

3.3 Who decides if and when girls are ready for school?

3.4 Who participates in any other important decisions about girls in your family?

\section{STEP 4: IDENTIFYING CORE INFLUENCERS ON MATTERS PERTAINING TO CHILD WELL-BEING}

Instructions: Refer back to names listed from name generator list. Mark the name generator list with an "I" next to the most influential people. Allow respondent to list up to 5 people. Use the following question:

4.1 In addition to people who participate in decisionmaking, who are the people who are most influential on your caregiving of your children?

\section{STEP 5: CREATE THE NETWORK MAP}

(Instructions: List all decisionmakers on the network diagram on Post-it Notes. Then list up to 5 most influential persons.)

Color code: Decisionmakers $=$ pink

Core influencers $=$ blue

Respondent (ego) $=$ green 


\section{STEP 6: DRAW ARROWS FOR ADVICE, ASSISTANCE, AND FINANCIAL SUPPORT}

Instructions: Next, draw arrows showing advice, help and financial support. The arrow should show the direction of the support. The arrow can be a one-way arrow $\rightarrow$ or a two-way arrow $\leftrightarrow$.

"I would like to know more about these people in your family and community who are concerned about the well-being of children in your family. We would like you to tell us about the people who are concerned about your child, and the types of concerns they have."

Advice (black lines and arrows)—I would like to ask you about people who give you advice about your child, or people you advise.

6.1 Who advises on feeding children in your family?

6.2 Did anyone advise you on when it was time to introduce foods other than breastmilk? Who?

6.3 Who advises on care when children in your family do not feel well?

6.4 Who advises about training your children to make sure they are well behaved?

6.5 Do people come to you for advice about their children? If yes, who?

Emotional support (green lines and arrows)—I would like to ask you about people who give you emotional support when you are worried or upset about your child.

6.6 Who gives you encouragement or emotional support when you are worried or upset about your child?

Help (red lines and arrows) - I would like to ask you about people who help you with taking care of children in your family, or people you help.

6.7 Who helps care for or feed your children?

6.8 Who helps treat your children when they are not well?

Financial support (blue lines and arrows)

6.9 Who help you pay for children's expenses when needed, or who asks you for financial help?

6.10 Who helps pay for things such as food or clothing or ceremonies?

6.11 Who helps pay for medicine?

6.12 Who helps pay for school fees?

6.13 Do you help out anyone when they need money? If yes, who?

\section{STEP 7: TOWER OF INFLUENCE}

Stack chips to represent who has the most influence over the way you give care for your daughter ( $1=$ least influence, $5=\mathbf{m o s t}$ influence)

\section{STEP 8: QUESTIONS ON EXCISION}

We would like to understand more about how people in your community make decisions about excision.

8.1 I know that there are campaigns for ending excision. How do you feel about this?

8.2 Where have you been told things about excision? What did you hear? 
8.3 (If formally educated): Did you hear about excision in school? (If yes,) what did you hear?

8.4 Do you think excision should be stopped? Why? Why not?

8.5 What changes have you seen in the practice over the years?

8.6 Do you know if there is a law banning excision? If no, skip to question 8.9.

8.7 What does the law say?

8.8 What is your opinion about the law? Please explain.

8.9 What is your opinion about excision? Do you think it should continue or be stopped?

8.10 Why?

8.11 Is there a difference in the way that circumcised and uncircumcised women are treated?

8.12 If you have gone or not, does that have an effect on finding a husband?

8.13 Who are the people for whom the practice is most important?

8.14 Who are the people who want it to stop?

\section{If respondent is female:}

8.15 Do you yourself remember undergoing excision? If no, skip to next section.

8.16 How old were you?

8.17 Did you go in a large group?

8.18 Did you stay in the bush or in town?

8.19 Did you stay afterwards to learn?

8.20 What sorts of things did you learn?

8.21 Was there a celebration afterwards?

8.22 Which parts of these traditions are important to keep?

8.23 What type of excision was practiced in your family? (Infibulation or other)

\section{STEP 9: QUESTIONS ON DECISIONMAKERS AND CORE INFLUENCERS}

(Instructions: Fill out one Decisionmaker and Core Influencer Survey form for each person on the network map. You should fill out one survey for each alter, but the questions are asked to ego.)

\section{STEP 10: NETWORK DENSITY GRID}

(Instructions: Use the Network Density Grid form to mark an "X" to indicate any decisionmakers and core influencers who DO NOT KNOW EACH OTHER.)

Note interview end time:

Interviewers: Please write a debrief on your observations and thoughts about the interview. 


\section{APPENDIX 3. NETWORK PARTNER NAME GENERATOR FORM}

\section{Network Partner Name Generator Form}

\begin{tabular}{|l|l|}
\hline Name & Date \\
\hline Interviewers & \\
\hline
\end{tabular}

\begin{tabular}{|c|c|c|c|}
\hline Name & $\begin{array}{c}\text { Relationship } \\
\text { (differentiate faux kin } \\
\text { from real kin) }\end{array}$ & $\begin{array}{l}\text { Nomination } \\
\text { questions }\end{array}$ & $\begin{array}{l}\text { Decisionmaker or } \\
\text { Core Influencer? }\end{array}$ \\
\hline \multicolumn{4}{|l|}{1} \\
\hline \multicolumn{4}{|l|}{2} \\
\hline \multicolumn{4}{|l|}{3} \\
\hline \multicolumn{4}{|l|}{4} \\
\hline \multicolumn{4}{|l|}{5} \\
\hline \multicolumn{4}{|l|}{6} \\
\hline \multicolumn{4}{|l|}{7} \\
\hline \multicolumn{4}{|l|}{8} \\
\hline \multicolumn{4}{|l|}{9} \\
\hline \multicolumn{4}{|l|}{10} \\
\hline \multicolumn{4}{|l|}{11} \\
\hline \multicolumn{4}{|l|}{12} \\
\hline \multicolumn{4}{|l|}{13} \\
\hline \multicolumn{4}{|l|}{14} \\
\hline \multicolumn{4}{|l|}{15} \\
\hline \multicolumn{4}{|l|}{16} \\
\hline \multicolumn{4}{|l|}{17} \\
\hline \multicolumn{4}{|l|}{18} \\
\hline \multicolumn{4}{|l|}{19} \\
\hline \multicolumn{4}{|l|}{20} \\
\hline \multicolumn{4}{|l|}{21} \\
\hline \multicolumn{4}{|l|}{22} \\
\hline \multicolumn{4}{|l|}{23} \\
\hline \multicolumn{4}{|l|}{24} \\
\hline \multicolumn{4}{|l|}{25} \\
\hline \multicolumn{4}{|l|}{26} \\
\hline \multicolumn{4}{|l|}{27} \\
\hline \multicolumn{4}{|l|}{28} \\
\hline \multicolumn{4}{|l|}{29} \\
\hline 30 & & & \\
\hline
\end{tabular}




\section{APPENDIX 4. DEMOGRAPHIC INFORMATION ON NETWORK PARTNERS}

\section{Decisionmaker and Core Influencer Survey}

\begin{tabular}{|l|l|}
\hline Respondent name: & Date: \\
\hline Interviewers: & Community: \\
\hline
\end{tabular}

Complete one survey for every decisionmaker or core influencer (alter) on the network map. Note: respondent (ego) provides this information, and not the named network partner (alter).

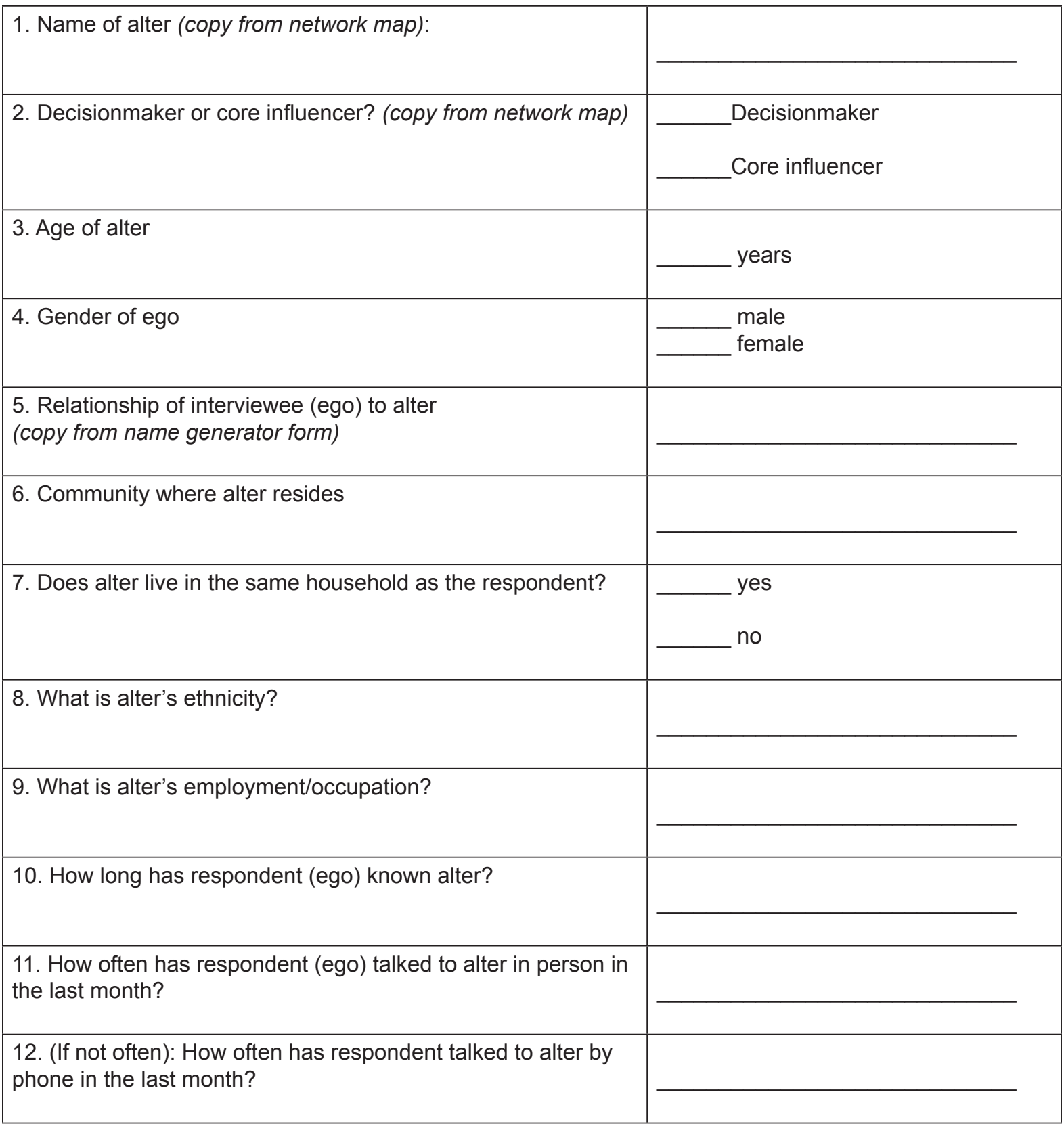




\begin{tabular}{|c|c|}
\hline 13. Does alter come from a family that practices excision? & $\begin{array}{r}\text { yes } \\
\text { no }\end{array}$ \\
\hline $\begin{array}{l}\text { 14. What is ego's opinion about the continuation of excision? } \\
\text { (use this question to turn the top chip of the tower of } \\
\text { influence: } \\
\text { red = excision should stop } \\
\text { white = excision should continue) }\end{array}$ & $\begin{array}{l}\text { excision should continue } \\
\text { excision should stop }\end{array}$ \\
\hline $\begin{array}{l}\text { 15. Does the respondent think that girls in alter's family are } \\
\text { undergoing excision? }\end{array}$ & $\begin{array}{r}\text { yes } \\
\text { no }\end{array}$ \\
\hline 16. Does ego approve if girls in ego's family undergo excision? & $\begin{array}{c}\text { yes } \\
\text { no }\end{array}$ \\
\hline 17. Did respondent (Ego) ever discuss excision with alter? & $\begin{array}{c}\text { yes } \\
\text { no }\end{array}$ \\
\hline 18. Does alter think that excision is against the law? & $\begin{array}{r}\text { yes } \\
\text { no }\end{array}$ \\
\hline $\begin{array}{l}\text { 19. If yes, does alter think it is important for people to follow the } \\
\text { law banning excision? }\end{array}$ & $\begin{array}{c}\text { yes } \\
\text { no }\end{array}$ \\
\hline 20. Tower of influence score for alter (copy from network map) & \\
\hline
\end{tabular}




\section{APPENDIX 5. NETWORK DENSITY GRID}

\section{Network Density Grid}

\begin{tabular}{|l|l|}
\hline Name: & Date: \\
\hline Interviewer: & \\
\hline
\end{tabular}

List decisionmakers and core influencers.

Does (name of network partner) know the others? (Place an X in a cell if people DO NOT know each other)

\begin{tabular}{|l|l|l|l|l|l|l|l|l|l|l|l|l|l|l|}
\hline & & 1 & 2 & 3 & 4 & 5 & 6 & 7 & 8 & 9 & 10 & 11 & 12 & 13 \\
\hline 1 & Name & & & & & & & & & & & & \\
\hline 2 \\
\hline 3
\end{tabular}




\section{APPENDIX 6. INSTRUCTIONS FOR ADMINISTRATION OF INSTRUMENTS}

\section{Ethnographic Network Interview with Individual Mothers}

Inclusion criteria:

1. Has a daughter between ages 3 months and 5 years

2. Comes from a family that once practiced excision

Pre-interview protocol:

1. Obtain informed consent.

2. Give the respondent a sheet with contact information for GRAG and the Ministry of Health so they can contact either if they have any questions or concerns following the interview.

3. Before the interview begins, you may want to try to determine if all of the decisionmakers are out of town.

The interview is broken down into 11 steps:

\section{STEP 1: RESPONDENT BACKGROUND}

This section includes basic demographic information about the respondent.

\section{STEP 2: NAME GENERATOR QUESTIONS}

The questions below should be used to complete the Network Partner Name Generator Form. For each person mentioned, obtain their name and their relationship to the respondent. Also record the number of the question that led to the mention of each name. It takes two people to complete this task: one person to ask the name generator questions and find out how the respondent (Ego) is related to that person, and one person to write the name, relationship and number of the questions that resulted in the name being generated. It is helpful if both interviewers sit next to each other so they can both look at the list of names being generated.

Note: when you write down relationship, differentiate faux kin from genuine kin.

Network Partner Name Generator Form

\begin{tabular}{|l|l|}
\hline Name Halima & Date 29 July, 2016 \\
\hline Interviewers Alhagy and Bettina & \\
\hline
\end{tabular}

\begin{tabular}{|l|l|l|l|}
\hline Name & $\begin{array}{l}\text { Relationship } \\
\text { (differentiate faux kin } \\
\text { from real kin) }\end{array}$ & $\begin{array}{l}\text { Nomination } \\
\text { Questions }\end{array}$ & $\begin{array}{l}\text { Decision-Maker or } \\
\text { Core Influencer? }\end{array}$ \\
\hline 1 Ndeye & sister & 2.1, & \\
\hline 2 Binta & Mother-in-law & $2.1,2.2,2.4$ & D \\
\hline 3 Lamin & husband & $2.2,2.8$ & D \\
\hline 4 Amina & Aunt (faux) & $2.4,2.7$ & \\
\hline 5 Nene & neighbor & $2.10,2.12$ & \\
\hline 6 Penda & sister & $2.3,2.11$ & I \\
\hline 7 Awa & Sister-in-law & $2.4,2.5,2.7$ & D \\
\hline 8 Fatou & friend & 2.8 & I \\
\hline 9 Codou & Friend and nurse & 2.5 & \\
\hline 10 Nanding & Friend and teacher & 2.10 & \\
\hline 11 Mohamed & brother & 2.15 & \\
\hline 12 & & & \\
\hline 13 & & & \\
\hline 14 & & & \\
\hline & & & \\
\hline
\end{tabular}


Refer back to list of network partners on the Name Generator form. Mark "D" next to people who are identified as decisionmakers OF MATTERS PERTAINING TO THE WELL-BEING OF GIRLS. These questions are not as general as the name generator questions. This is specifically about decisionmakers who are involved in matters pertaining to the respondent's daughter. There is no limit on the number of people who can be named. Please encourage the respondent to explain why she is selecting the persons she names as decisionmakers. This narrative is an important part of our data. We want to hear her description.

\section{STEP 4: IDENTIFYING CORE INFLUENCERS ON MATTERS PERTAINING TO CHILD WELL-BEING}

Refer back to names listed on the name generator list. Mark the name generator list with an "I" next to the most influential people. Allow respondent to list up to 5 people.

Note that with decisionmakers, there is no limit on the number of people who can be named. But for core influencers, people can only list up to 5 people. As you then create the network map, it is acceptable for people to add new decisionmakers or core influencers. But if they add more than $\mathbf{5}$ core influencers, they need to decide who to remove. Please allow the respondent to explain why she is selecting each person. This narrative is an important part of our data. We want to hear her description.

\section{STEP 5: CREATE THE NETWORK MAP}

List all decisionmakers on the network diagram on Post-it Notes. Then list up to 5 most influential persons. Place the Post-it Notes on a large sheet of easel-paper, and explain this process to the informant.

Color code: Decisionmakers $=$ pink

Core influencers $=$ blue

Respondent (ego) $=$ green

Place a wooden block next to each name to indicate gender:

$$
\begin{aligned}
& \text { Square }=\text { male } \\
& \text { Round }=\text { female }
\end{aligned}
$$

Note: It is OK if the respondent, ego, wants to add different decisionmakers or core influencers to the map. But there can be only $\mathbf{5}$ core influencers. If they add a sixth influential person, one must be removed. There is no maximum on decisionmakers, but the maximum number of core influencers is 5 . 


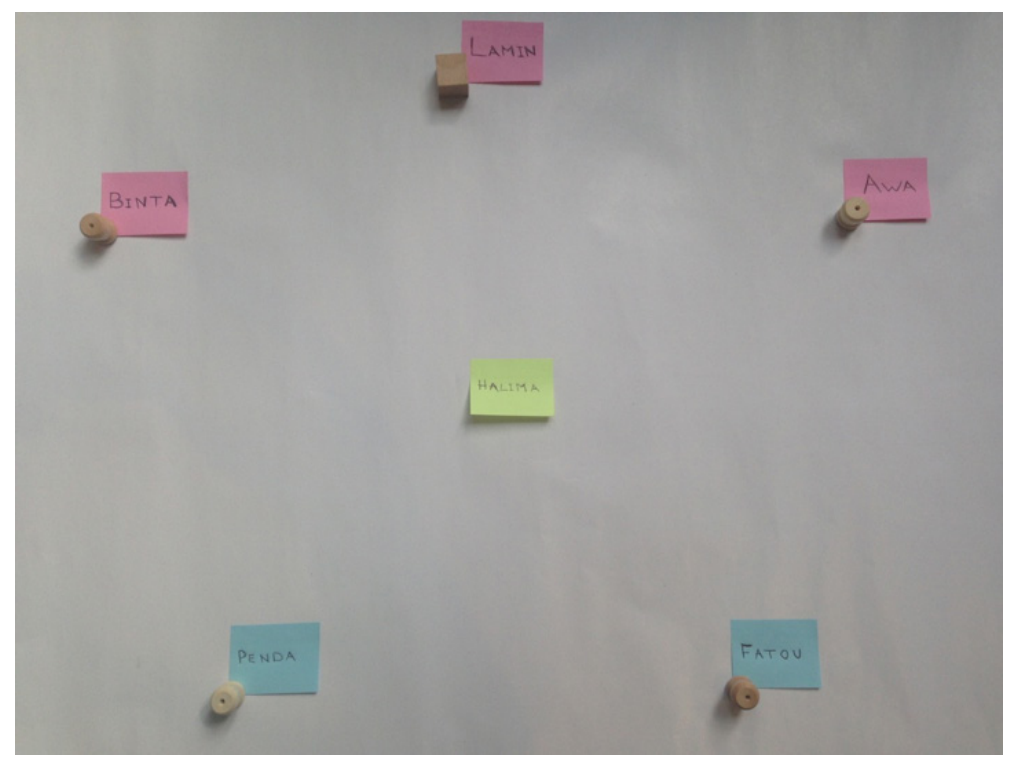

\section{STEP 6: DRAW ARROWS FOR ADVICE, ASSISTANCE, AND FINANCIAL SUPPORT}

Next, draw arrows showing advice, help and financial support. The arrow should show the direction of the support. The arrow can be a one-way arrow $\rightarrow$ or a two-way arrow $\leftrightarrow$.

You can introduce the topic by saying: "I would like to know more about these people in your family and community who are concerned about the well-being of your child. We would like you to tell us about the people who are concerned about your child, and the types of concerns they have." Then draw lines and arrow for the following categories:

- Advice—black lines and arrows

- Emotional support—green lines and arrows

- Help—red lines and arrows

- Financial support-blue lines and arrows

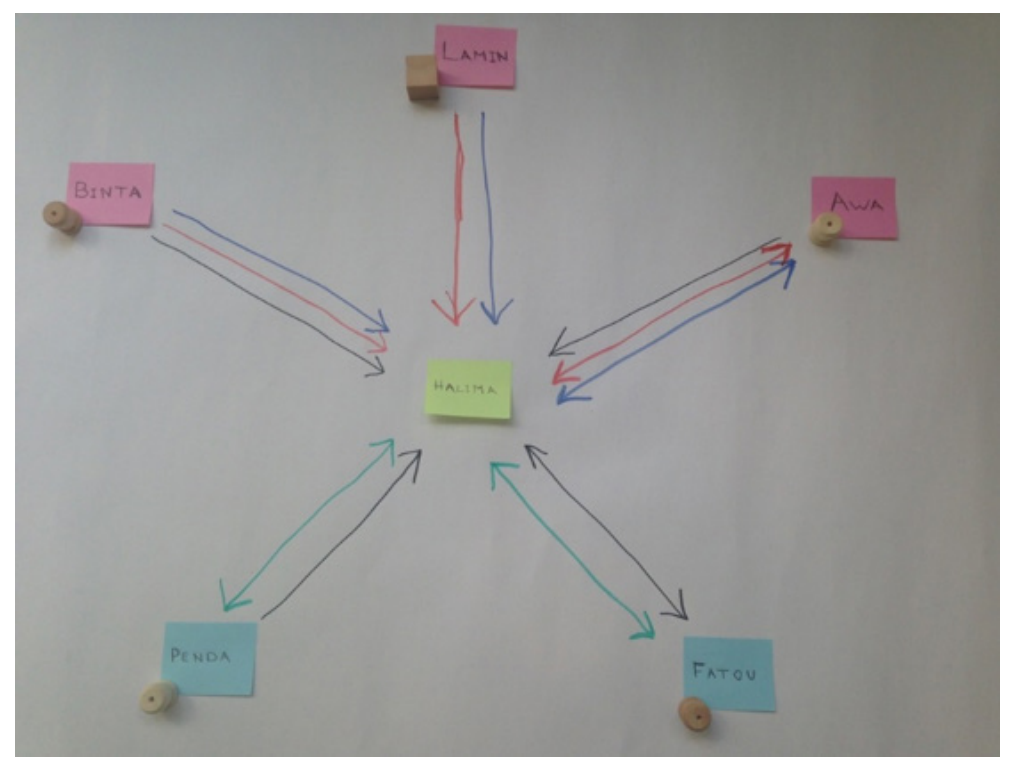




\section{STEP 7: TOWER OF INFLUENCE}

Stack chips to represent who has the most influence over the way you give care for your daughter.

\section{$1=$ least influence}

\section{$5=$ most influence}

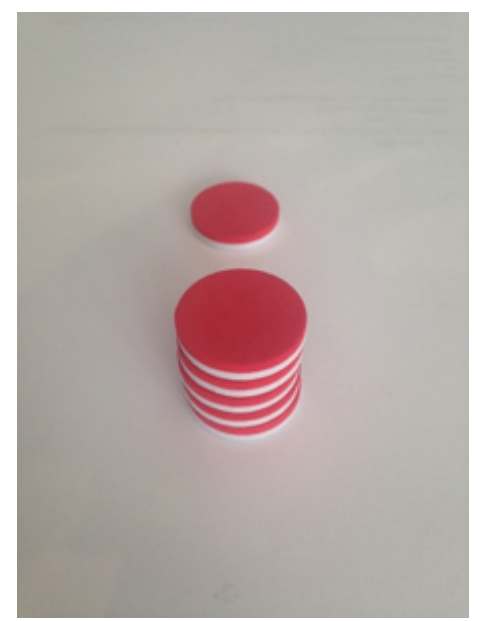

Everyone must have at least 1 chip. If they have no influence at all, they should not be listed as a core influencer or decisionmaker.

The top chip will face up red if the network partner is believed to want excision to stop. The chip will face up white if the network partner is believed to support the continuation of excision.

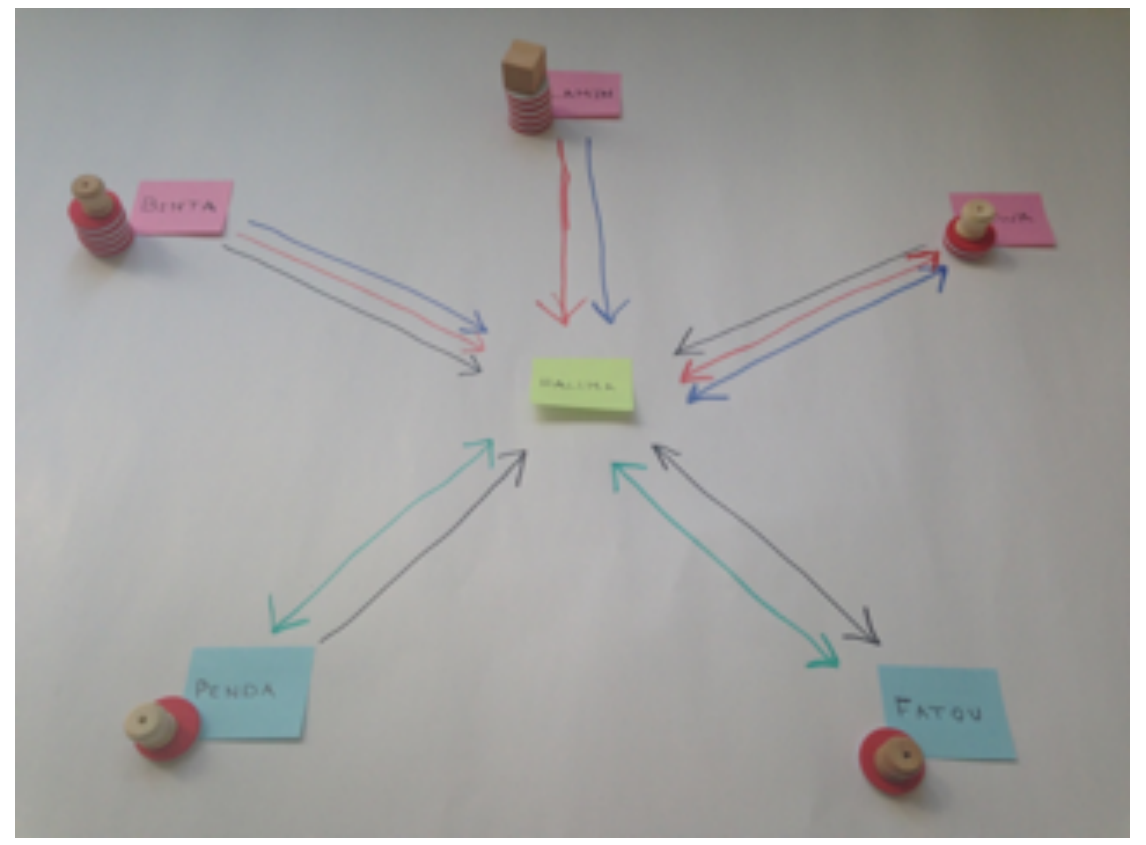

In this example, Binta and Lamin have a tower of influence with 5 chips. The top chip for Binta faces up red. This means Binta wants to see excision stop. The top chip for Lamin faces up white. This means Lamin wants excision to continue. The other network partners have fewer chips in their tower of influence: Awa has 2 chips, and Penda and Fatou each have 1 chip. 
In step 11 you will ask the respondent if it is OK for you to talk to the two people with the highest tower of influence. This would be Binta and Lamin.

Take a photograph of the completed Network Map. Assure the informant that we will delete the picture after we make a computer image of it with ID numbers replacing names.

\section{STEP 8: QUESTIONS ON EXCISION}

Mothers of girls between the ages of 3 months and 5 years will be asked their views on excision. They will also be asked to recall details of their own circumcision and that of their daughter (if she has been cut already).

\section{STEP 9: QUESTIONS ON DECISIONMAKERS AND CORE INFLUENCERS}

Fill out one Decisionmaker and Core Influencer Survey form for each person on the network map. You should fill out one survey for each alter, but the questions are asked to ego. If the mother being interviewed does not know an alter's opinion on excision or the law banning excision, ask her what she believes his or her opinion is, most likely.

\section{Decision-Maker and Core Influencer Survey}

\begin{tabular}{|l|l|}
\hline Respondent Name: Halima & Date: 29 July, 2016 \\
\hline Interviewers: Alhagy and Bettina & Community: Koular \\
\hline
\end{tabular}

(Complete one survey for every decision-maker or core influencer (Alter) on the network map. Note: respondent (Ego) provides this information, and not the named network partner (Alter))

\begin{tabular}{|c|c|}
\hline 1. Name of Alter (copy from network map): & Binta \\
\hline $\begin{array}{l}\text { 2. Decision-maker or core influencer? (copy from } \\
\text { network map) }\end{array}$ & $\begin{array}{r}\text { X_Decision maker } \\
\text { Core influencer }\end{array}$ \\
\hline 3. Age of Alter & $\ldots 54$ years \\
\hline 4. Sex of Ego & _ \\
\hline $\begin{array}{l}\text { 5. Relationship of interviewee (Ego) to Alter } \\
\text { (copy from name generator form) }\end{array}$ & mother-in-law \\
\hline 6. Community where Alter resides & Koular \\
\hline $\begin{array}{l}\text { 7. Does Alter live in the same household as the } \\
\text { respondent? }\end{array}$ & $\begin{array}{c}X_{\text {_n yes }} \\
\text { no }\end{array}$ \\
\hline 8. What is Alter's ethnicity? & Mandinka \\
\hline
\end{tabular}




\section{STEP 10: NETWORK DENSITY GRID}

Use the Network Density Grid form to mark an "X" to indicate any decisionmakers and core influencers who DO NOT KNOW EACH OTHER.

In this example, Penda and Binta do not know each other.

\section{Network Density Grid}

\begin{tabular}{|l|l|}
\hline Name Halima & Date 29 July, 2016 \\
\hline Interviewer Alhagy and Bettina & \\
\hline
\end{tabular}

List decision-makers and core influencers.

Does (name of network partner) know the others? (Place an X in a cell if people DO NOT know each other)

\begin{tabular}{|l|l|l|l|l|l|l|l|l|l|l|l}
\hline & & 1 & 2 & 3 & 4 & 5 & 6 & 7 & 8 & 9 & 10 \\
\hline & Name & Binta & Lamin & Awa & Penda & Fatou & & & & & \\
\hline 1 & Binta & & & & X & & & & & & \\
\hline 2 & Lamin & & & & & & & & & & \\
\hline 3 & Awa & & & & & & & & & & \\
\hline 4 & Penda & X & & & & & & & & & \\
\hline 5 & Fatou & & & & & & & & & & \\
\hline 6 & & & & & & & & & & & \\
\hline 7 & & & & & & & & & & & \\
\hline 8 & & & & & & & & & & & \\
\hline 9 & & & & & & & & & & & \\
\hline
\end{tabular}

\section{STEP 11: ASK FOR PERMISSION TO TALK TO THE TWO PEOPLE WITH THE HIGHEST INFLUENCE TOWERS (IF THEY LIVE IN THE SAME COMMUNITY)}

If an influential decisionmaker or core influencer is unavailable, you can interview just one. But try to get two people. You should assure the mother that you will not share the information that she gave in the interview with anyone else. They will not see the network map she has helped you create.

Note interview end time.

\section{Follow-up}

After the interview, please write a debrief on your observations and thoughts about the interview. This may include questions that the respondent was hesitant to answer, issues that appeared through body language, etc. 


\section{Ethnographic Network Interview with Influential Person Nominated by the Mother}

Inclusion criteria:

1. Was named by a mother previously interviewed and had a large tower of influence

2. Lives in the same community as the mother

Pre-interview protocol:

1. Obtain informed consent.

2. Give the respondent a sheet with contact information for GRAG and the Ministry of Health so they can contact either if they have any questions or concerns following the interview.

You do not need to be concerned whether network partners are available. You will not be doing snowball sampling from this interview. You will not be interviewing the network partners that this ego lists.

This interview is similar to the one done with mothers, but the guideline questions are slightly different. Make sure you use the "Interview Guidelines for Person Nominated by the Mother Who Had a Large Tower of Influence." This guideline is broken down into only 10 steps:

\section{STEP 1: RESPONDENT BACKGROUND}

This section includes basic demographic information about the respondent.

\section{STEP 2: NAME GENERATOR QUESTIONS}

The questions below should be used to complete the Network Partner Name Generator Form. This time the new respondent is the ego, and you write every alter she mentions. For each person mentioned, obtain his or her name and relationship to the respondent. Also record the number of the question that led to the mention of each name. This will be a new sheet, and not an extension of the one written during the interview with the mother. In this example, Binta is now the ego. She has listed her daughter-in-law Halima as one of the decisionmakers.

It takes two people to complete this task: one person to ask the name generator questions and find out how the respondent (ego) is related to that person, and one person to write the name, relationship, and number of the question that resulted in the name being generated. It is helpful if both interviewers sit next to each other so they can both look at the list of names being generated.

Note: when you write down the relationship, differentiate faux kin from genuine kin.

Network Partner Name Generator Form

\begin{tabular}{|c|c|c|c|}
\hline \multicolumn{2}{|l|}{ Name Binta } & \multicolumn{2}{|c|}{ Date 30 July, 2016} \\
\hline \multicolumn{4}{|c|}{ Interviewers Dem and Aminata } \\
\hline Name & $\begin{array}{l}\text { Relationship } \\
\text { (differentiate faux kin } \\
\text { from real kin) }\end{array}$ & $\begin{array}{l}\text { Nomination } \\
\text { Questions }\end{array}$ & $\begin{array}{l}\text { Decision-Maker or } \\
\text { Core Influencer? }\end{array}$ \\
\hline 1 Lamin & son & $2.1,2.3$ & D \\
\hline 2 Momadou & son & $2.1,2.3$ & D \\
\hline 3 Halima & Daughter-in-law & $2.4,2.7$ & D \\
\hline 4 Ibrahim & Husband & 2.8 & \\
\hline 5 Awa & Daughter-in-law & $2.7,2.11$ & D \\
\hline 6 Souadou & cousin & $2.1,2.8$ & 1 \\
\hline 7 Assiatou & Sister-in-law & $2.1,2.8,2.10$ & 1 \\
\hline 8 Anna & niece & 2.11 & \\
\hline 9 Adama & Niece (faux kin) & 2.11 & \\
\hline 10 Miriam & friend & $2.8,2.10,2.12$ & 1 \\
\hline 11 Valerie & friend & 2.12 & \\
\hline \multicolumn{4}{|l|}{12} \\
\hline 13 & & & \\
\hline
\end{tabular}


Refer back to the list of network partners on the Name Generator form. Mark "D" next to people who are identified as decisionmakers OF MATTERS PERTAINING TO THE WELL-BEING OF GIRLS. These questions are not as general as the name generator questions. They are also worded slightly differently than the questions for mothers. Instead of asking about a specific young girl, the questions ask about "girls in your family." This is specifically about decisionmakers who are involved in matters pertaining to girls in the respondent's family. There is no limit on the number of people who can be named. Please encourage the respondent to explain why she is selecting the persons she names as decisionmakers. This narrative is an important part of our data. We want to hear her description.

Important note: The decisionmaker list might not be identical to the one produced by the mother. This is OK. During the interview, it is extremely important that you do not reveal anything that the mother told you. Everything she told you must be kept strictly confidential.

\section{STEP 4: IDENTIFYING CORE INFLUENCERS ON MATTERS PERTAINING TO CHILD WELL-BEING}

Refer back to the names listed from name generator list. Mark the name generator list with an "I" next to the most influential people. Allow respondent to list up to 5 people.

Note that with decisionmakers, there is no limit on the number of people who can be named. But for core influencers, people can only list up to 5 people. As you then create the network map, it is acceptable for people to add new decisionmakers or core influencers. But if they add more than 5 core influencers, they need to decide who to remove. Please allow the respondent to explain why she is selecting each person. This narrative is an important part of our data. We want to hear her description.

\section{STEP 5: CREATE THE NETWORK MAP}

This step involves creating a new network map for this respondent. This is a new ego. Do not show the respondent the network map created by another interviewee. This will be a new map, and it will also be kept confidential.

List all decisionmakers on the network diagram on Post-it Notes. Then list up to 5 most influential persons. Place the Post-it Notes on a large sheet of easel-paper, and explain this process to the informant.

Color code: Decisionmakers $=$ pink

Core influencers $=$ blue

Respondent (ego) $=$ green

Place a wooden block next to each name to indicate gender:

$$
\begin{aligned}
& \text { Square }=\text { male } \\
& \text { Round }=\text { female }
\end{aligned}
$$

Note: It is OK if the respondent, ego, wants to add different decisionmakers or core influencers to the map. But there can be only 5 core influencers. If they add a sixth influential person, one must be removed. There is no maximum on decisionmakers, but the maximum number of core influencers is 5 . 


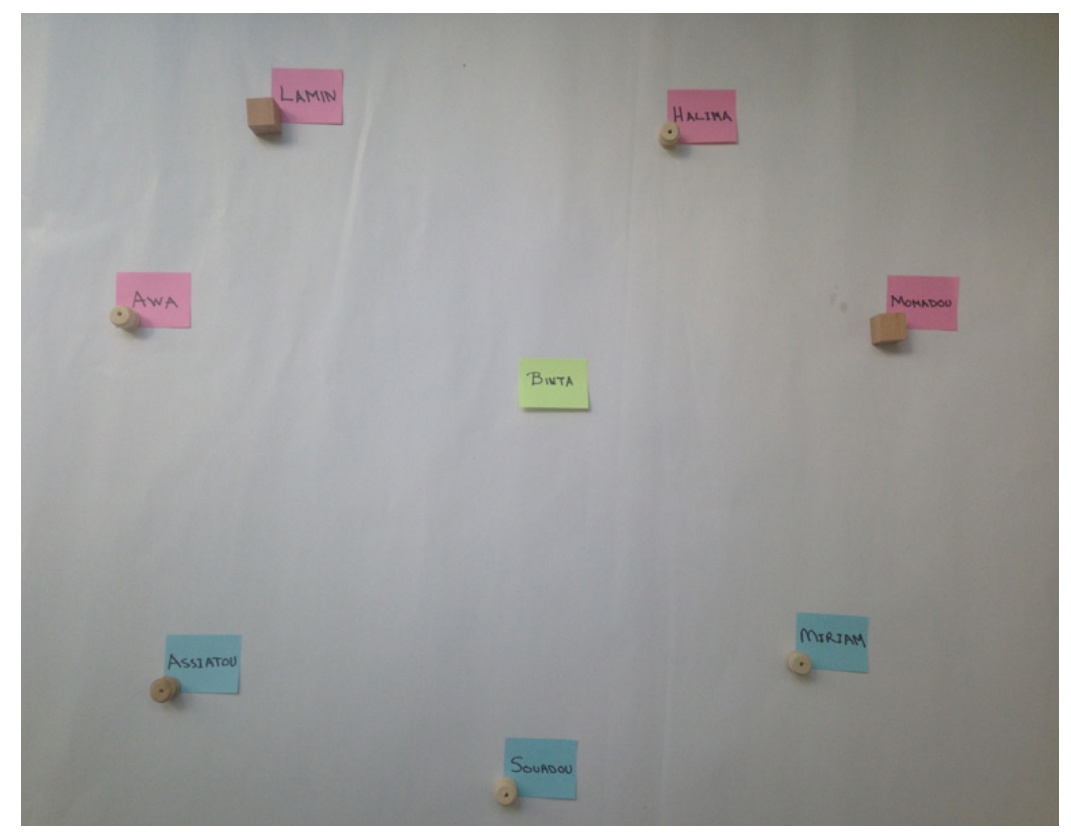

\section{STEP 6: DRAW ARROWS FOR ADVICE, ASSISTANCE, AND FINANCIAL SUPPORT}

Next, draw arrows showing advice, help and financial support. The arrow should show the direction of the support. The arrow can be a one-way arrow $\rightarrow$ or a two-way arrow $\leftrightarrow$.

You can introduce the topic by saying: "I would like to know more about these people in your family and community who are concerned about the well-being of children in your family. We would like you to tell us about the people who are concerned about your children, and the types of concerns they have." Then draw lines and arrow for the following categories:

- Advice-black lines and arrows

- Emotional support-green lines and arrows

- Help—red lines and arrows

- Financial support-blue lines and arrows

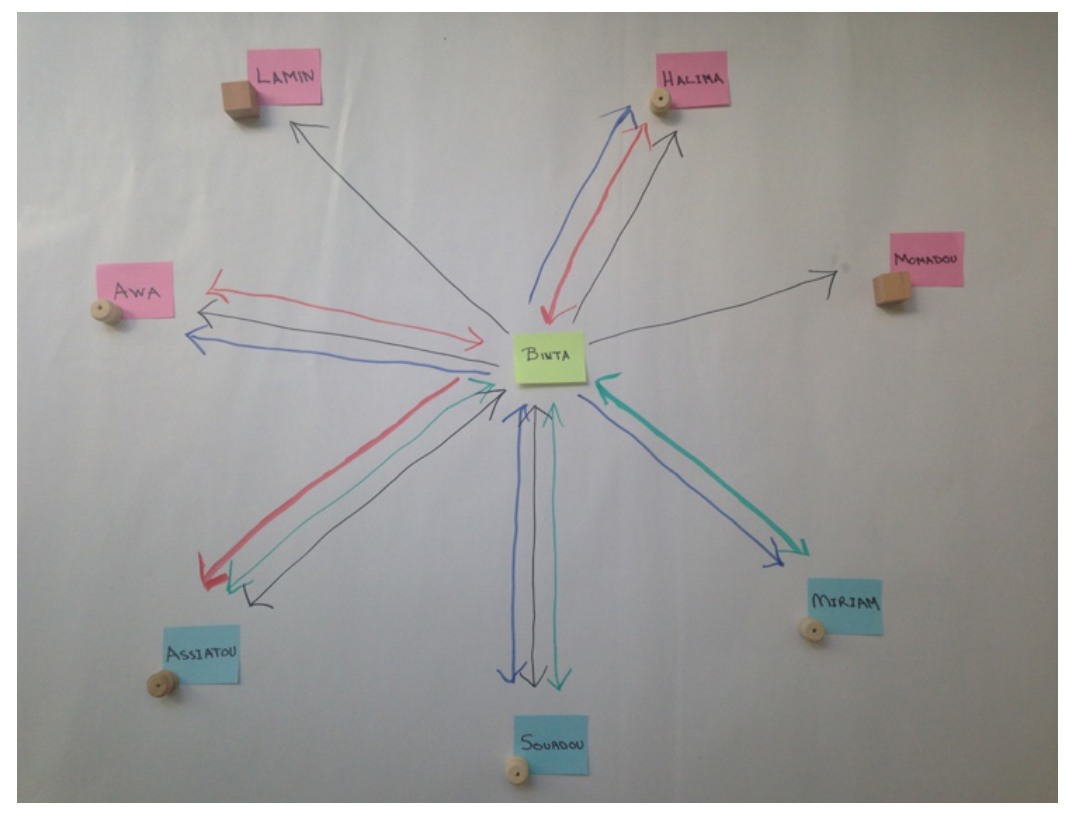




\section{STEP 7: TOWER OF INFLUENCE}

Stack chips to represent who has the most influence over the way you care for your girls in your family.

\section{$1=$ least influence}

\section{$5=$ most influence}

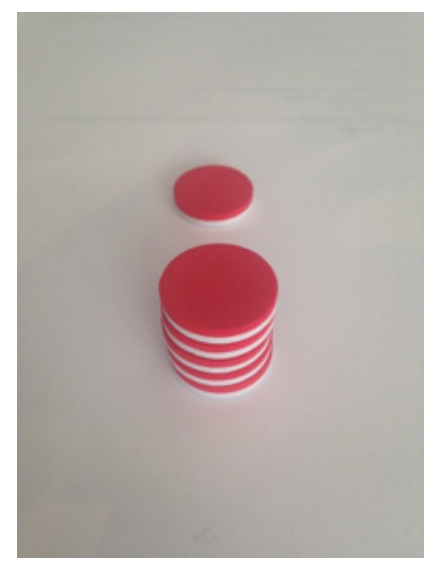

Everyone must have at least 1 chip. If they have no influence at all, they should not be listed as a core influencer or decisionmaker.

Take a photograph of the completed network map. Assure the informant that we will delete the picture after we make a computer image of it with ID numbers replacing names.

In this example, Assiatou has the highest tower of influence, and the top chip is facing up red, meaning that she wants excision to stop.

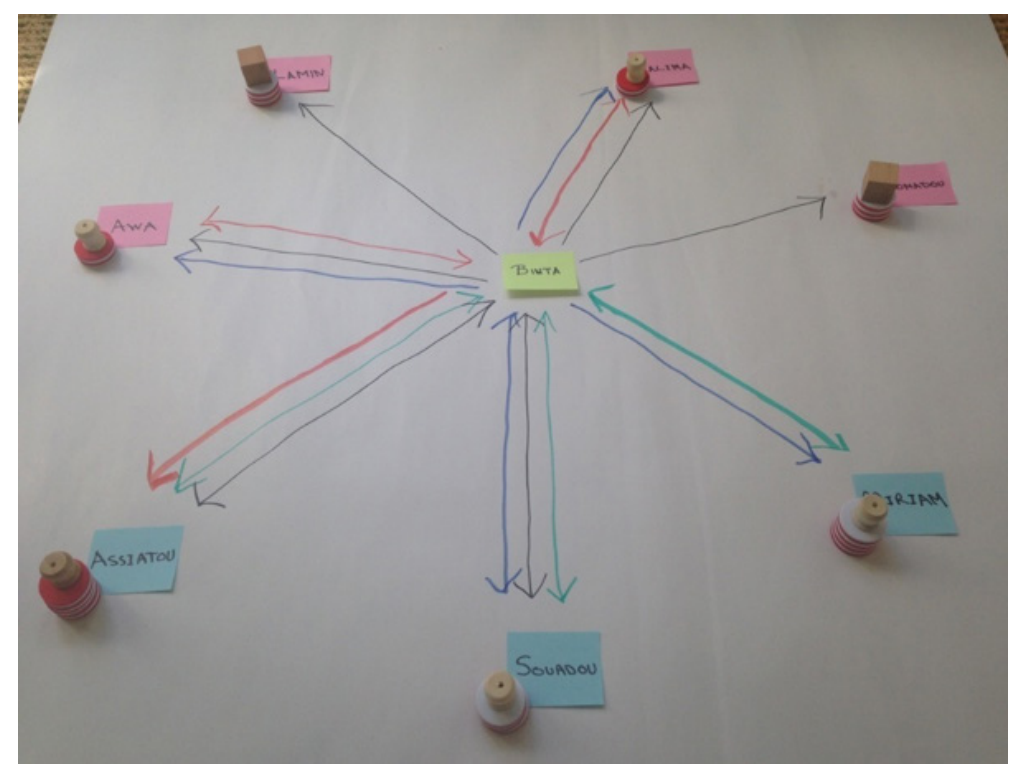

\section{STEP 8: QUESTIONS ON EXCISION}

Respondents will be asked about their views on excision. If the respondent is female, she will also be asked to recall details of her own circumcision. You do not need to ask about excision status of girls in the respondents' family. 


\section{STEP 9: QUESTIONS ON DECISIONMAKERS AND CORE INFLUENCERS}

Fill out one Decisionmaker and Core Influencer Survey form for each person on the network map. You should fill out one survey for each alter, but the questions are asked to the ego. If the person being interviewed does not know an alter's opinion on excision or the law banning excision, ask him or her what he or she believes the alter's opinion is, most likely.

\begin{tabular}{|l|l|}
\hline \multicolumn{2}{|c|}{ Decision-Maker and Core Influencer Survey } \\
\hline Respondent Name: Binta & Date: 30 July, 2016 \\
\hline Interviewers: Dem and Aminata & Community: Koular \\
\hline
\end{tabular}

(Complete one survey for every decision-maker or core influencer (Alter) on the network map. Note: respondent (Ego) provides this information, and not the named network partner (Alter))

\begin{tabular}{|c|c|c|}
\hline & Name of Alter (copy from network map): & Souadou \\
\hline & $\begin{array}{l}\text { Decision-maker or core influencer? (copy from } \\
\text { network map) }\end{array}$ & _ Decision maker \\
\hline 3. & Age of Alter & 50 years \\
\hline & Sex of Ego & $\mathrm{x}_{\mathrm{f} \text { female }}^{\text {male }}$ \\
\hline & $\begin{array}{l}\text { Relationship of interviewee (Ego) to Alter } \\
\text { (copy from name generator form) }\end{array}$ & cousin \\
\hline 6. & Community where Alter resides & Koular__ \\
\hline & $\begin{array}{l}\text { Does Alter live in the same household as the } \\
\text { respondent? }\end{array}$ & $\begin{array}{l}{ }_{2} \text { yes } \\
x_{\text {nno }}\end{array}$ \\
\hline & What is Alter's ethnicity? & Mandinka_ \\
\hline
\end{tabular}

\section{STEP 10: NETWORK DENSITY GRID}

Use the Network Density Grid form to mark and "X" to indicate any decisionmakers and core influencers who DO NOT KNOW

\section{EACH OTHER.}

In this example Miriam and Assiatiou do not know each other.

\section{Network Density Grid}

\begin{tabular}{|l|l|}
\hline Name Binta & Date 30 July, 2016 \\
\hline Interviewer Dem and Aminata & \\
\hline
\end{tabular}

List decision-makers and core influencers.

Does (name of network partner) know the others? (Place an X in a cell if people DO NOT know each other)

\begin{tabular}{|l|l|l|l|l|l|l|l|l|l|l}
\hline & & 1 & 2 & 3 & 4 & 5 & 6 & 7 & 8 & 9 \\
\hline & Name & Halima & Lamin & Awa & Momadou & Souadou & Assiatou & Miriam & & \\
\hline 1 & Halima & & & & & & & & & \\
\hline 2 & Lamin & & & & & & & & & \\
\hline 3 & Awa & & & & & & & & & \\
\hline 4 & Momadou & & & & & & & & & \\
\hline 5 & Souadou & & & & & & & & & \\
\hline 6 & Assiatou & & & & & & & X & & \\
\hline 7 & Miriam & & & & & & X & & & \\
\hline 8 & & & & & & & & & & \\
\hline 9 & & & & & & & & & & \\
\hline
\end{tabular}

\section{DIFFERENCE BETWEEN THIS INTERVIEW AND THE ONE DONE WITH MOTHERS:}

There is no Step 11 in this interview. We will not ask to talk to any of the network partners named by this respondent. The snowball recruitment stops here.

Note interview end time

\section{Follow-up}

After the interview, please write a debrief on your observations and thoughts about the interview. This may include questions that the respondent was hesitant to answer, issues that appeared through body language, etc. 


\section{ACKNOWLEDGMENTS}

This reference guide draws on experiences implementing a study titled, The End of Female Genital Mutilation/Cutting in Senegal: Tracing Social Networks, Investigating the Role of Gender and Intergenerational Influence. The study is led by Amadou Moreau and Bettina Shell-Duncan. We acknowledge the contributions of the following GRAG research team members:

- Moustapha Diagne

- Awa Coulibaly

- Alpha Ousmane Diallo

- Modou Dem

- Sokhna Aminata Dia

- Helene Benga

- Amadou Tidiane Ly 
Evidence to End FGM/C: Research to Help Girls and Women Thrive generates evidence to inform and influence investments, policies, and programmes for ending female genital mutilation/cutting in different contexts. Evidence to End FGM/C is led by the Population Council, Nairobi in partnership with the Africa Coordinating Centre for the Abandonment of Female Genital Mutilation/Cutting (ACCAF), Kenya; the Global Research and Advocacy Group (GRAG), Senegal; Population Council, Nigeria; Population Council, Egypt; Population Council, Ethiopia; MannionDaniels, Ltd. (MD); Population Reference Bureau (PRB); University of California, San Diego (Dr. Gerry Mackie); and University of Washington, Seattle (Prof. Bettina Shell-Duncan).

\section{POPULATION} COUNCIL

Ideas. Evidence. Impact.

The Population Council confronts critical health and development issues-from stopping the spread of HIV to improving reproductive health and ensuring that young people lead full and productive lives. Through biomedical, social science, and public health research in 50 countries, we work with our partners to deliver solutions that lead to more effective policies, programs, and technologies that improve lives around the world. Established in 1952 and headquartered in New York, the Council is a nongovernmental, nonprofit organization governed by an international board of trustees. www.popcouncil.org

GRAG is dedicated to the promotion and protection of minorities' rights to safeguard their well-being. This is initiated by the introduction of effective programs tailored to the needs of the target communities. Through strategic and applied research, training, and advocacy, GRAG seeks to identify and target areas of improvement for effective program initiatives. Our team is intent on engaging communities to make informed decisions regarding their sexual and reproductive health, family planning, and nutritional needs. We therefore strive to initiate programs that strengthen the capacities and protection of vulnerable populations by helping them access the necessary information and services they require.

http://globalresearchandadvocacygroup.org

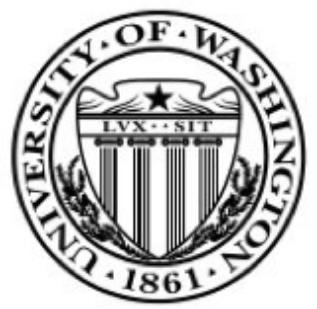

The University of Washington is one of the world's preeminent public universities. Our impact on individuals, our region, and the world is profound-whether we are launching young people into a boundless future or confronting the grand challenges of our time through undaunted research and scholarship. We turn ideas into impact and transform lives and our world. www.washington.edu

Suggested Citation: Shell-Duncan, B., Moreau, A., Smith, S., Shakya, H. (2018). "Reference Guide for Data Collection: Qualitative Social Network Interviews." Evidence to End FGM/C: Research to Help Girls and Women Thrive. New York: Population Council.

For additional information, contact:

Bettina Shell-Duncan at bsd@uw.edu

Amadou Moreau at amoreau@globalresearchandadvocacygroup.org

Please address any inquiries about the Evidence to End FGM/C program consortium to:

Dr Jacinta Muteshi, Project Director, jmuteshi@popcouncil.org

(C) 2019 The Population Council, Inc.

Funded by:

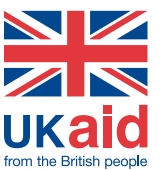

This document is output from a programme funded by UK Aid from the UK government for the benefit of developing countries. However, the views expressed and information contained in it are not necessarily those of, or endorsed by the UK government, which can accept no responsibility for such views or information, or for any reliance placed on them. 